\title{
INHIBITION OF NITRIC OXIDE SYNTHESIS BY DEXAMETHASONE INCREASES SURVIVAL RATE IN Plasmodium berghei-INFECTED MICE
}

Danilo Reymão Moreira ${ }^{1}$; Ana Carolina Musa Gonçalves Uberti ${ }^{1}$, Antonio Rafael

Quadros Gomes ${ }^{1}$; Michelli Erica Souza Ferreira ${ }^{1}$; Rogério Silva Santos ${ }^{1}$; Michael

Dean Green²; José Ricardo dos Santos Vieira; Maria Fani Dolabela; Sandro

Percário $^{1 \star}$

${ }^{1}$ Oxidative Stress Research Laboratory, Institute of Biological Sciences, Federal University of Pará, Av. Augusto Corrêa, 01, Belém, Pará, Brazil, 66075-110. alydan@hotmail.com (DRM), acmusa23@yahoo.com.br (ACMGU), rafaelquadros13@hotmail.com (ARQG), michelli quimifarm@yahoo.com.br (MESF), rogeriosst@gmail.com (RSS), irvieira@ufpa.br (JRSV), percario@ufpa.br, spercario49@gmail.com (SP).

2 Division of Parasitic Diseases and Malaria, the US Centers for Disease Control and Prevention, 1600 Clifton Rd. NE, Mailstop G49, Atlanta, Georgia, United States of America, 30329, mdg4@cdc.gov (MDG).

${ }^{3}$ Institute of Health Sciences, Federal University of Pará, Av. Augusto Corrêa, 01, Belém, Pará, Brazil, 66075-110. fani@ufpa.br (MFD).

\section{* Corresponding author}




\section{Abstract}

Malaria still presents great epidemiologic importance by its high incidence in the world and potential clinical severity. Plasmodium parasites are highly susceptible to changes in the redox balance and the relationship between the redox state of the parasite and host cells is very complex and involves nitric oxide (NO) synthesis. Thus, the present study is aimed at evaluating the effects of NO synthesis on the redox status, parasitemia evolution and survival rate of Plasmodium bergheiinfected mice. Two-hundred and twenty-five mice were infected with Plasmodium berghei and submitted to the stimulation or inhibition of NO synthesis. The stimulation of NO synthesis was performed through the administration of Larginine, while its inhibition was made by the administration of dexamethasone. Inducible NO synthase (iNOS) inhibition by dexamethasone promoted an increase in the survival rate of $P$. berghei-infected mice and data suggested the participation of oxidative stress in brain as a result of plasmodial infection, as well as the inhibition of brain NO synthesis, which promoted survival rate of almost $90 \%$ of the animals until the $15^{\text {th }}$ day of infection, with possible direct interference of ischemia and reperfusion syndrome, as seen by increased levels of uric acid. Inhibition of iNOS caused a decrease of parasitemia and increased survival rate of infected animals, suggesting that the synthesis of $\mathrm{NO}$ may stimulate a series of compensatory redox effects that, if overstimulated, may be responsible for the onset of severe forms of malaria.

Key words: Nitric oxide, malaria, oxidative stress, dexamethasone, L-arginine, Plasmodium berghei, Inducible nitric oxide synthase, parasitemia, survival rate. 


\section{INTRODUCTION}

Malaria is an acute febrile infectious disease whose etiological agents are protozoa of genus Plasmodium. Five species are known to infect man: Plasmodium vivax, $P$. falciparum, $P$. malariae, $P$. ovale and $P$. knowlesi. Although there are evidences of the occurrence of the disease since 2700 B.C. (Cox, 2002), it is of epidemiological importance still today by its high incidence in the world and potential clinical severity, causing considerable social and economic losses in the population at risk, especially to ones in precarious conditions of dwelling and sanitation (WHO, 2011).

According to the World Health Organization (WHO) malaria is a significant public health problem in 108 countries and causes approximately 130 million new cases each year (WHO, 2014), resulting in 445 thousand deaths in 2016 (WHO, 2017). About $90 \%$ of these deaths occur in sub-Saharan Africa and it is estimated that the disease kills a child every 30 seconds (WHO, 2011).

Usually, the severe cases of the disease are related to the infection by $P$. falciparum. Among the complications that are worth mentioning are cerebral malaria and pulmonary complications (Botelho et al. 1996; Van der Heyde et al. 2000; Taylor et al. 2006; Penet et al. 2007). However, the mechanisms that trigger the pathogeny of malaria and the appearance of severe forms are yet not fully elucidated and additional studies are necessary.

In this regard, several authors recently discuss the involvement of free radicals in the physiopathogenesis of malaria (Huber et al. 2002; Dondorp et al. 2003; Pabon et al. 2003; Omodeo-Salé et al. 2003; Jaramillo et al. 2003; Becker et al. 2004; Yazar et al. 2004; Wilmanski et al. 2005; Kumar and Bandyopadhyay 2005; Dey et al. 2009; Percário et al. 2012; Vale et al. 2015). This involvement can be related to the pathogenic mechanisms triggered by the parasite (Potter et al. 2005), as well as by the production of free radicals (Keller et al. 2004), and antioxidant defenses (Sohail et al. 2007) by host cells as an attempt to fight the infection. 
During the development of blood stages of $P$. falciparum, trophozoites increase the viscosity of erythrocytes, by causing modifications on the cell surface 75 that allow its adhesion to the endothelial wall of capillaries, which seems to be a mechanism of defense of the parasite, preventing the passage of parasitized erythrocytes by the spleen and its consequent destruction (Luse and Miller 1971). This cytoadherence phenomenon is mediated by expressed parasite proteins, via stimulation of gene var, on the surface of infected red cell, interrupting the blood flow and harming the tissues irrigated by the obstructed vessels (Ferreira et al.

81 2004; Pettersson et al. 2005), providing the conditions for the participation of ischemia and reperfusion syndrome (IRS), responsible for free radical production and, consequently, causing oxidative stress (Halliwell and Gutteridge 2015).

In fact, the level of oxidative stress is high in patients infected by $P$. vivax, as detected by the elevation of plasma levels of malondialdehyde - biochemical marker of lipid peroxidation (Farombi et al. 2003) - even in patients with non-severe forms of the disease (Pabon et al. 2003).

Additionally, oxidative changes in erythrocytes infected with $P$. falciparum seem to be associated to the accelerated aging of these cells and contribute to the development of the anemia displayed by these individuals (Omodeo-Salé et al. 2003). The development of anemia can promote changes in the circulatory physiology, leading to the existence of moments of alternate hypoxia and tissue oxygenation at basal levels, thus, another inductor factor of IRS.

Moreover, in response to the infection, activated macrophages and neutrophils act as the natural defense mechanism of the host organism and these generate a large amount of free radicals by activation of respiratory burst, causing an imbalance between the formation of oxidant species and the activity of antioxidants. This imbalance triggers the oxidative stress, being an important mechanism of human host in response to microbial infections that, in the case of malaria, can lead to the death of parasites. humans are increased in comparison to non-infected controls (Sohail et al. 2007). 
103

104

105

106

107

108

109

110

111

112

113

114

115

116

117

118

119

120

121

122

123

124

125

126

127

128

129

130

In these cases, oxidative stress seems to be the result of an increase in free radicals, and not a consequence of the decrease in the levels of antioxidants, reinforcing the suggestion that oxidative stress is an important mechanism induced by the infection (Pabon et al. 2003).

In fact, Plasmodium is highly susceptible to alterations in the redox balance, which can contribute to clinical manifestations of the severe cases of the disease, such as cerebral malaria (Narsaria et al. 2012). In parallel, the relationship between the redox state of the parasite and host cells is very complex and involves production of nitric oxide (NO; Becker et al. 2004; Gomes et al. 2015).

Nevertheless, the role of NO in malaria is still controversial. Some researchers say that cerebral malaria results from the production of high amounts of NO in order to promote the death of parasites (Favre et al. 1999; Maneerat et al. 2000), whereas others defend the suggestion that cerebral malaria arises from a low bioavailability of this gas (Gramaglia et al. 2006).

Perterson et al. (2007), demonstrated that NO synthesis derived from ingested blood in the digestive tract of the mosquito, induces the formation of toxic derivatives, limiting the development of the parasite. As to protect themselves from the damage induced by these toxic nitrogenated derivatives, the mosquito produces pyridoxines, antioxidant enzymes capable of synthetizing NO in response to parasitemia (Herrera-Ortiz et al. 2004).

Nahrevania \& Dascombe (2006) identified the increase of NO synthesis in $P$. berghei-infected mice and verified its correlation with the increase of the activity of immunologic cells (lymphocytes CD19, macrophages and monocytes).

In fact, some researchers suggest a protective role of nitric oxide in the development of severe malaria and indicate it as possible adjuvant in malaria drug therapy (Yeo et al. 2007, 2008; Dhangadamajhi et al. 2009). As suggested by Planche et al. (2010), the activation of NOS II is essential for the additional production of $\mathrm{NO}$ and elimination of the parasite. 
131

132

133

134

135

136

137

138

139

140

141

142

143

144

145

146

147

148

149

150

151

152

153

154

155

156

157

158

159

On the other hand, Cabrales et al. (2011) associated the development of cerebral manifestations of the inadequacy of NO production, which seems to be essential in maintaining cerebral circulatory hemodynamics.

In mice deficient of interleukin 4 (IL-4), it was found that the increase of iNOS expression and the activity of natural killer cells producing IFN- $y$, resulted in protection of animals even in the initial phase of infection by $P$. berghei (Saeftel et al. 2004).

Moreover, some parasitic molecules are well known as NO inducers, such as the malarial pigment hemozoin, which associated to IFN- $\gamma$, is a potent NO inducer in macrophages, involving the kinase regulated extracellular signaling (ERK) pathway and nuclear factor kappa B (NF-kB). It is also known that in the hepatic stage, the defense mechanisms are strictly related to the production of IFN-y by NK cells, with posterior synthesis of NO (Saeftel et al. 2004). In addition, it was found that hemozoin is also responsible for the activation of macrophages by mechanisms partially dependent on NO (Jaramillo et al. 2005) and other ROS, such as superoxide $\left(\mathrm{O}_{2}{ }^{-}\right)$and hydrogen peroxide $\left(\mathrm{H}_{2} \mathrm{O}_{2}\right.$ : Brinkmann et al. 1984).

Similarly, increased levels of iNOS in human monocytes are associated with non-worsening malaria in patients infected by $P$. falciparum (Chiwakata et al. 2000).

Syarifah et al. (2003), studying $P$. berghei-infected mice susceptible and resistant to the development of cerebral malaria, observed that cytokine expression was increased in resistant animals in relation to susceptible, as well as the expression of NO, worth mentioning the high production of TNF- $\alpha$ in resistant mice, suggesting that the activation of macrophages is significantly greater in those animals.

Three isoforms of nitric oxide synthase enzymes (NOS) were described so far, with two constitutive forms and one inducible form. Constitutive forms produce low amounts of NO for a long period, apparently being responsible for the physiological production of NO. The inducible form (iNOS or NOS II) is activated by 
160

161

162

163

164

165

166

167

168

169

170

171

172

173

174

175

176

177

178

179

180

181

182

183

184

185

186

187

188

189

factors, such as bacterial lypopolysaccharide (LPS) and cytokines (TNF- $\alpha$ e IFN- $\gamma$ ), producing large amounts of NO in a short space of time (Försterman and Sessa 2012).

All NOS enzymes use L-arginine as substrate, as well as molecular oxygen $\left(\mathrm{O}_{2}\right)$ and reduced nicotinamide adenine dinucleotide phosphate (NADPH) as cosubstrates, and flavine-adenine dinucleotide (FAD), flavine-mononucleotide (FMN) and (6R-)5,6,7,8-tetrahydro-L-biopterine (BH4) as cofactors (Försterman and Sessa 2012). The administration of L-arginine has been employed to stimulate the activity of iNOS in several studies, yet with controversial results (Percário et al. 2012).

On the other hand, NOS enzymes can be selectively inhibited. Among the most used inhibitors, N-nitro-L-arginine methyl ester (L-NAME) and N-monomethylL-arginine (L-NMMA) inhibit both forms of the enzyme, while aminoguanidine and dexamethasone selectively inhibit iNOS (Walker et al. 1997).

Dexamethasone is a glucocorticoid drug and acts on nuclear receptors directly interfering in gene expression in a variety of cell types (Katzung and Trevor 2017) and modulating the transcription of genes involved in the control of inflammatory process (Barnes et al. 1993). Since the beginning of the 1990s, some authors identified the effect of dexamethasone inhibiting iNOS expression in most diverse cell types: mesangial cells (Pfeilschifter and Schwarzenbach 1990), murine macrophages (Di Rosa et al. 1990), human endothelial cells (Radomski et al. 1990), rat hepatocytes (Geller et al. 1994), murine fibroblasts (Gilbert and Herschman 1993), and human epithelial cells (Kleinert et al. 2004). De Vera et al. (1997) attributes this action of dexamethasone by the inhibition of NFKB and to the activation of its inhibitory factor (IFKB). Regardless of the route used by dexamethasone, there is no doubt that NOS inhibition is independent of L-arginine concentration and greatly affects the expression of mRNA for the inducible enzyme (Korhonen et al. 2002; Skimming et al. 2003).

Administering dexamethasone to $P$. berghei infected mice significantly reduces symptoms of cerebral malaria (Neill and Hunt 1995; Sanni et al. 1998) 
In the present study it was demonstrated that the selective inhibition of iNOS by dexamethasone reduced the progression of parasitemia in $P$. berghei-infected mice and increased the survival rate of the animals.

\section{METHODS}

194 Two-hundred and twenty-five male Swiss mice (Mus musculus), young adults (25-

$19535 \mathrm{~g}$ ), from the Evandro Chagas Institute (Belem, PA, Brazil) were randomly

196 divided into three groups, each of them further divided into five sub-groups ( $n=15$

197 each), according to time of animals' euthanasia (one, five, ten, fifteen or twenty 198 days after inoculation), and samples of lung tissue and blood were collected for the 199 evaluation of oxidative stress markers, total antioxidant status, uric acid and 200 assessment of percentage of parasitemia, as follows:

201 Positive control groups ( $\mathrm{N}=15$ for each sub-group): animals were inoculated with $202 P$. berghei-infected erythrocytes and received $10 \mu \mathrm{l}$ of sterile distilled water per 25 $203 \mathrm{~g}$ of body weight (gavage) two hours prior to the inoculation of $P$. berghei and daily, 204 until the day of animals' euthanasia.

205 Dexamethasone groups ( $\mathrm{N}=15$ for each sub-group): animals were inoculated with $206 P$. berghei in the same way that groups PC and treated with dexamethasone, as 207 described below, until the day of animals' euthanasia.

208 L-Arginine groups ( $\mathrm{N}=15$ for each sub-group): animals were inoculated with $P$. 209 berghei in the same way that groups PC and simultaneously treated with L210 arginine, as described below, until the day of animals' euthanasia.

211 All animals were assigned into sub-groups by simple randomization using the sub212 group sequence generated after sortition (Suresh 2011) and were maintained in 213 the vivarium at the Federal University of Pará (UFPA, Belém, PA, Brazil) in 
214 polystyrene cages containing five animals each, kept under $12 \mathrm{~h}$ light/dark cycles,

215 controlled temperature $\left(25^{\circ} \mathrm{C}\right)$, and received rodent chow (Labina ${ }^{\mathrm{TM}}$, Presence,

216 Brazil), and tap water ad libitum for one, five, ten, fifteen or twenty days after

217 infection and, at the end of each period, animals were submitted to heparin

218 administration (100 UI heparin sulfate, ip.), anesthetized with $50 \mu$ of

219 intraperitoneal ketamine (5\%)-xylazine (2\%), sample collection, and underwent

220 euthanasia by exsanguination. Absolutely all efforts were made to minimize

221 suffering to animals.

222 After thoracotomy, blood samples were obtained by cardiac puncture of the right

223 ventricle and both lungs and brain were removed. The project followed the

224 international guidelines for research with experimental animals and procedures

225 were reviewed and approved by the Ethics Committee in Research with

226 Experimental Animals of the Federal University of Pará - CEPAE/UFPA (Report

227 No. MED0126/2013).

228 Features of the animal model

229 Swiss mice are widely used as a malaria model and presents the same pattern of 230 infection progression and basic features of lung and cerebral malarias of other

231 mice species. Moreover, $P$. berghei possesses genomic sequences similar to $P$.

232 falciparum (Otto et al. 2014) and cause clinical features on animals that mimic

233 human falciparum malaria (Penet et al. 2007). Taken together, the 234 histopathological features described are similar to those displayed in severe 235 malaria human cases.

236 Malaria induction 
237 Mice were kept in the vivarium for two weeks and underwent clinical examination

238 prior malaria induction through intraperitoneal inoculation of $10^{6} P$. berghei ANKA-

239 infected erythrocytes (in $0.2 \mathrm{~mL}$ sterile saline solution). The strain of $P$. berghei

240 was supplied by the Neurochemistry Laboratory of the Federal University of Pará -

241 UFPA and three times replicated in Swiss mice before being used in animals of this

242 study.

243 Treatments

244 Dexamethasone (Teuto, Cat \# 095214): administered in the dose of $5 \mathrm{mg} / \mathrm{Kg}$ of 245 animal weight.

246 L-arginine (Sigma Aldrich, Cat \# A5006): prepared in 0.9\% PBS, and administered

247 in a dose of $120 \mathrm{mg} / \mathrm{Kg}$ of animal weight (Chatterjee et al. 2007).

248 Both dexamethasone and L-arginine were administered $24 \mathrm{~h}$ prior infection and 249 every $24 \mathrm{~h}$ henceforth, until the day of animal euthanasia.

\section{Tissue processing}

251 After removal, lungs and brain were perfused with PBS to wash out the blood

252 trapped inside. The tissue was weighed and added to PBS in the ratio of 1:10 253 (m:v). The homogenization process was performed in an ultrasonic cell disruptor 254 (D Cel; Thornton, Indaiatuba, Brazil). During the process, the glass beaker 255 containing the material was kept on ice to prevent sample damage. The 256 homogenate was centrifuged at $175 \times g(15 \mathrm{~min})$ and the supernatant collected and

257 stored in a freezer at $-20^{\circ} \mathrm{C}$ until analyzed.

\section{Technical Procedure}

259 Along with blood parasitemia determination, laboratory measurements of trolox 260 equivalent antioxidant capacity (TEAC), thiobarbituric acid reactive substances 
261 (TBARS), Uric Acid (AU), and nitrites and nitrates (NN) were performed in

262 duplicate on tissue samples. Internal controls and standards were inserted in each

263 batch for the quality assurance of determinations.

264 Determination of parasitemia

265 Plasmodium berghei-infected erythrocytes were counted on blood smears obtained

266 by puncture of the caudal vein of animals on the day of euthanasia (one, five, ten,

267 fifteen, and twenty days of infection). After drying at room temperature, the smear

268 was fixed with methanol for $2 \mathrm{~min}$ and stained with Giemsa for $10 \mathrm{~min}$.

269 Subsequently, slides were washed in tap water and, after drying, erythrocytes were

270 counted on an optical microscope (Olympus, CX2) with 100x magnification.

271 Determination of Trolox Equivalent Antioxidant Capacity (TEAC)

272 Trolox (6-hydroxy-2,5,7,8-tetramethylchromane-2-carboxylic acid; Sigma-Aldrich

$27323881-3)$ is a powerful antioxidant water-soluble vitamin $E$ analogue. The method

274 proposed by Miller et al. (1993) modified by Re et al. (1999) was followed, a

275 colorimetric technique based on the reaction between ABTS (2,2'-Azino-bis-3-

276 ethylbenzothiazoline-6-sulfonic acid; Sigma-Aldrich; 1888) with ammonium

277 persulfate potassium $\left(\mathrm{K}_{2} \mathrm{~S}_{2} \mathrm{O}_{8}\right.$; Sigma-Aldrich; 60490), producing the radical cation

$278 \mathrm{ABTS}^{\bullet}+$, chromophore of green/blue color. The addition of antioxidants to $\mathrm{ABTS}^{\bullet}+$

279 reduces it again to ABTS, on a scale dependent on antioxidant capacity,

280 concentration of antioxidants and duration of the reaction. This can be measured

281 by spectrophotometry by observing the change in absorbance read at $734 \mathrm{~nm}$ for

282 five minutes (Fento, Sao Paulo, Brazil; 800 XI). Finally, the total antioxidant activity

283 of the sample is calculated as its relationship with the reactivity of the Trolox as 
284 standard, through the implementation of standard curve under the same

285 conditions.

286

\section{Determination of Thiobarbituric Acid Reactive Substances (TBARS)}

287 TBARS is a method that evaluates lipid peroxidation and was used as an indicator 288 of oxidative stress. This technique is based on the reaction of malondialdehyde 289 (MDA), among other substances, with thiobarbituric acid (TBA; Sigma-Aldrich 290 T5500), in low pH and high temperature, yielding MDA-TBA complex of pink color, 291 and absorbance peak at $535 \mathrm{~nm}$.

292 The technical procedure was performed according to the protocol proposed by 293 Khon and Liversedge (1944), adapted by Percario et al. (1994). In brief: initial TBA 294 solution $(10 \mathrm{nM})$ was prepared in phosphate monobasic potassium $\left(\mathrm{KH}_{2} \mathrm{PO}_{4} 75\right.$ 295 mM; Synth; 35210) adjusted to pH 2.5 with acetic acid. Two hundred and fifty $\mu \mathrm{L}$ 296 of sample was added to $500 \mu \mathrm{L}$ of TBA solution, mixed and placed in a water bath $297\left(95^{\circ} \mathrm{C}\right.$ x $\left.60 \mathrm{~min}\right)$; after cooling at room temperature, $2.0 \mathrm{ml}$ of 1 -butanol was added, 298 vortex mixed and subsequently centrifuged (175 $\times \mathrm{g} \times 15 \mathrm{~min}) ; 1.0 \mathrm{ml}$ of the 299 supernatant was collected and read at 535 nm (Fento, São Paulo, Brazil; 800 XI). 300 1,1,3,3, tetraethoxypropane (Sigma-Aldrich; T9889) was used for the 301 implementation of the standard curve.

$302 \quad$ Nitrites and nitrates (NN)

303 Much of nitric oxide released into the bloodstream is swept by hemoglobin in 304 erythrocytes or converted to nitrite $\left(\mathrm{NO}_{2}{ }^{--}\right)$in the presence of molecular oxygen. 305 Nitrite reacts with oxyhemoglobin, leading to the formation of nitrate $\left(\mathrm{NO}_{3}{ }^{\bullet-}\right)$ and 306 methemoglobin. Due to its stability, $\mathrm{NO}_{2}{ }^{\bullet-}$ has been widely used to confirm the prior 
existence of NO. The evaluation of this parameter was performed by means of spectrophotometry (Kit Total Nitrite/Nitrate, R \& D Systems, KGE001). This technique is based on the quantitative determination of $\mathrm{NO}$, involving the enzyme nitrate reductase, which converts nitrate to nitrite, followed by colorimetric detection of nitrite as a product of pink color, produced by the Griess reaction and that absorbs visible light at $540 \mathrm{~nm}$ (PerkinElmer, Victor X3). Nitrite concentration was calculated based on the absorbance found in the nitrites standard curve.

\section{Uric acid}

Performed using the Kit Uric acid UOD-ANA (Labtest, Cat. 51-4/30).

The test is based on the production of $\mathrm{H}_{2} \mathrm{O}_{2}$ from the reaction of uric acid with oxygen and water, catalyzed by uricase. This $\mathrm{H}_{2} \mathrm{O}_{2}$ reacts with acid 3,5-dichloro-3hydroxybenzene sulphonate (DHBS) and 4-aminoantipyrine in the presence of peroxidase, producing dye antipirylquinonimine. Samples were read at a spectrophotometer at 520nm (Biospectro, SP-22, Brazil).

\section{Statistical Analysis}

Sample size was calculated by the method proposed by Dell et al. (2002). The occurrence of discrepant values (outliers) was investigated through calculation of interquartile range, which calculates the difference between the third quartile (Q3) and the first quartile (Q1), called dj. Any value lower than Q1 - 3/2 dj or greater than Q3 + 3/2 dj, was considered as outlier and, therefore, removed from mathematical calculations.

Aiming at investigating the existence of statistically significant differences between the studied variables between Groups, we applied ANOVA two factors, when the assumption of normality and homoscedasticity was met, or the Mann-Whitney test, 
331 when the assumption of normality was not met, which occurred in the case of

332 variable PARASITEMIA. The tests used to access the normality and

333 homoscedasticity of the variables were Kolmogorov-Smirnov and Levene tests,

334 respectively. When the null hypothesis between mean differences between the

335 variables of the study groups was rejected, Tukey's test was applied, and when a

336 statistically significant difference between medians was detected, Dunn's test was

337 applied. In addition, within the same group the differences between the initial

338 values (1 day of infection) and late values (20 days of infection) were studied by

339 the Student's unpaired t test.

340 The existence of correlation between the variables was also analyzed by Pearson's

341 correlation coefficient, considering all points obtained separately for each group

342 studied. For the statistically significant correlations, intensities were assigned as

343 follows: $r$ up to $0.30(r<0.30)$ as weak correlation; $r$ between 0.31 and $0.70(0.31<$

$344 \quad r<0.70)$, as moderate correlation; $r$ between 0.71 and $1.00(0.71<r<1.00)$ as

345 strong correlation.

346 For the purposes of tests ANOVA and Mann-Whitney, statistical package

347 SigmaStat version 3.5 was used, whereas for the calculation of correlations the

348 statistical package SPSS version 17.0 was used. All statistical tests were applied

349 considering the significance level of $5 \%(p<0.05)$.

350 Availability of Data and Materials

351 Data and full description of methods and materials are available at Zenodo 352 repository, at https://zenodo.org/record/45202\#.VqeqifLVyid. 
354

355

356

357

358

359

360

361

362

363

364

365

366

367

368

369

370

371

372

373

374

375

376

377

\section{RESULTS}

As expected, parasitemia of infected animals progressively evolved in all groups, but the rate of progression was lower in dexamethasone-treated animals, which presented lower values than the other two groups at the end of the period of 20 days $\left(\mathrm{p}=2.8 \times 10^{-5}\right.$ vs. L-arginine and $\mathrm{p}=0.0227$ vs. control; Fig. 1). L-argininetreated animals presented numerically higher values than the control group, but without statistical significance $(p=0.3048)$.

Similarly, the survival rate of dexamethasone-treated animals was significantly greater than that of the other groups, which behaved in a similar way, with $60 \%$ of animals alive at the end of the period of 20 days of infection (Fig. 2).

\section{TEAC:}

For the lung samples, all groups showed a slight decrease of TEAC values along the period of infection, however without statistically significant differences (Fig. 3A). Nevertheless, at the end of 20 days of infection, the group of animals treated with dexamethasone presented statistically lower values than the other two groups $(p=0.0281$ vs. L-ARGININE and $p=0.0033$ vs. CONTROL). For brain samples a similar behavior was observed, however an important decrease of TEAC after 10 days of infection was identified ( 1 day vs. 10 days, $p=0.0009$ for L-ARGININE and $\mathrm{p}=7 \times 10^{-6}$ for DEXAMETHASONE), with both treated groups presenting values lower than the control group $(\mathrm{p}=0.0360$ vs. L-ARGININE and $\mathrm{p}=0.0261$ vs. DEXAMETHASONE). However, after the $10^{\text {th }}$ day of infection the DEXAMETHASONE group presented an increase in TEAC values, displaying statistically higher values than the other groups $(p=0.0357 v s$. L-ARGININE and $p=$ 0.0005 vs. CONTROL). 


\section{TBARS:}

Although none of the groups have presented important variation during the period of infection, Group L-ARGININE presented higher pulmonary TBARS values than the DEXAMETHASONE group at the end of the experiment $(p=0.0282)$. On the other hand, for brain samples, Group L-ARGININE showed progressive evolution over the period of the infection, with higher TBARS values in the $20^{\text {th }}$ day of infection in relation to the first day $\left(p=4.7 \times 10^{-7}\right)$, but with no differences in relation to the other groups (Fig. 4).

The collective analysis of the values of TEAC and TBARS shows a quite unique pattern: while for lung samples the values of TEAC obtained are found in a high range of absolute values (9-12 $\mu \mathrm{M})$, brain samples are in a low range (4-8 $8 \mathrm{M})$, whereas TBARS values presenting opposing behavior, i.e. for lung samples the values are in low range $(80-120 \mathrm{nmol} / \mathrm{mL})$ and brain samples in high range (160$280 \mathrm{nmol} / \mathrm{mL})$.

\section{Nitrites and nitrates:}

No significant differences in the evolution of NN levels in any of the groups throughout the period of infection were seen, nor between groups for the lung samples (Fig. 5). However, for brain samples, group DEXAMETHASONE presented lower values than the other two groups during the studied period, culminating with statistically significant differences in the $20^{\text {th }}$ day $(p=0.0058$ vs. LARGININE and $\mathrm{p}=0.0201$ vs. CONTROL).

\section{Uric acid (AU):}

No temporal variation in $\mathrm{AU}$ values for lung samples in any of the groups were found (Fig. 6). However, Group L-ARGININE presented lower values than the other 
402 two groups from the first to the $15^{\text {th }}$ day of infection. Similarly, for brain samples,

403 group L-ARGININE presented lower values than the other groups, with statistical

404 significance at the $20^{\text {th }}$ day of infection $(\mathrm{p}=0.0395$ vs. CONTROL and $\mathrm{p}=0.0407$ vs.

405 DEXAMETHASONE). In contrast, group DEXAMETHASONE presented

406 progressive behavior over the infection time, with brain AU values significantly

407 greater for the $20^{\text {th }}$ day in comparison to the first day $\left(p=3.9 \times 10^{-4}\right)$. Another 408 noteworthy observation is that pulmonary AU values stood in a higher range (40-

$409140 \mathrm{mg} / \mathrm{dL})$ than the brain $(10-55 \mathrm{mg} / \mathrm{dL})$ for all groups.

410 Correlation studies:

411 PARASITEMIA vS. TBARS

412 The correlation between TBARS and PARASITEMIA revealed the existence of a 413 negative and significant correlation only for the lung samples from the group 414 DEXAMETHASONE (Additional file 1 Fig. 1; $r=-0.29 ; p=0.026$ ). The CONTROL 415 group presented a negative correlation, however without statistical significance $(r=-$ $4160.10 ; p=0.20$ ), while for group L-ARGININE this correlation showed positive but 417 non-significant values $(r=0.06 ; p=0.673)$. For brain samples a positive trend was 418 observed for all groups, but only with significance for group L-ARGININE 419 (Additional file 1 Fig. 2; $r=0.46 ; p=0.002$ ).

420 TBARS vs. URIC ACID

421 A positive correlation was observed for these parameters in both samples and for 422 groups CONTROL (Additional file 1 Fig. $3-4 ; r=0.33$ and $p=0.02$, for lung; $r=0.45$ 423 and $p=0.050$, for brain), and DEXAMETHASONE ( $r=0.26$ and $p=0.041$, for lung; $424 r=0.28$ and $p=0.045$, for brain). For group L-ARGININE, in both samples, the 
425 values of the coefficient of correlation approached zero $(r=0.08$ and $p=0.140$, for

426 lung; $r=0.03$ and $p=0.858$, for brain).

427 NN vs. TBARS

428 For lung samples the existence of significant correlation for any of the studied 429 groups was not observed (Additional file 1 Fig. 5). However, for brain samples, 430 both groups CONTROL and DEXAMETHASONE presented significant positive 431 correlations (Additional file 1 Fig. 6; $r=0.30$ and $p=0.048$ and $r=0.34$ and $p=0.014$, 432 respectively).

433 TEAC vs. TBARS

434 The existence of positive correlation in both samples and for both groups 435 CONTROL (Additional file1 Fig. 7-8; $r=0.32$ and $p=0.024$, for lung; $r=0.50$ and 436 $p=0.009$, for brain) and DEXAMETHASONE, $(r=0.23$ and $p=0.031$, for lung; $r=0.27$

437 and $p=0.050$, for brain) was seen. For the group L-ARGININE, in both samples, the 438 values of the coefficient of correlation were negligible $(r=0.05$ and $p=0.821$, for 439 lung; $r=0.14$ and $p=0.374$, for brain).

$440 \quad$ NN vs. PARASITEMIA

441 No significant correlation was found for any of the groups, nor for any of the 442 samples studied (Additional file1 Fig. 9-10).

443 Other Correlations

444 In addition to the studies of correlation presented, we tested the following 445 correlations: TEAC vs. NN (Additional file 1 Fig. 11-12); TEAC vs. URIC ACID 446 (Additional file 1 Fig. 13-14), TEAC vs. PARASITEMIA (Additional file 1 Fig. 15-16), 447 NN vs. URIC ACID (Additional file 1 Fig. 17-18), and URIC ACID vs. 448 PARASITEMIA (Additional file 1 Fig. 19-20). 
bioRxiv preprint doi: https://doi.org/10.1101/497966; this version posted December 19, 2018. The copyright holder for this preprint (which was not certified by peer review) is the author/funder. This article is a US Government work. It is not subject to copyright under 17 USC 105 and is also made available for use under a CCO license. 
450

451

452

453

454

455

456

457

458

459

460

461

462

463

464

465 than the other groups (Fig. 1).

466 It is important to highlight that dexamethasone is a non-steroid anti-inflammatory

467 drug that acts through iNOS mRNA synthesis inhibition (Korhonen et al. 2002). In

468 this sense, it is possible that NO acts oxidatively, both inducing the worsening of

469 the disease, as favoring the increasing of parasitemia.

470 Therefore, the effect of dexamethasone on the evolution of the parasitemia can

471 promote inhibition of oxidative stress, as may be suggested by the existence of a

472 negative correlation between TBARS and PARASITEMIA found only for the 473 animals of group dexamethasone (Additional file Fig. 1). In the same way, the 
474 effect of L-arginine is consistent with the effect found in this correlation for the

475 animals of Group L-ARGININE, where there is the reversal of this pattern,

476 presenting positive values of correlation.

477 Contrary to that mentioned by some authors (Yeo et al. 2007, 2008;

478 Dhangadamajhi et al. 2009; Planche et al. 2010; Cabrales et al. 2011) that attribute

479 a protective role to nitric oxide in malaria, mice treated with L-arginine remained 480 with percentage of parasitemia and survival rate comparable to group CONTROL

481 (Fig.1-2), suggesting that NO synthesis is not involved among the initial 482 mechanisms of host defense and, therefore, may not contribute to the elimination 483 of parasites. However, the mentioned studies have measured the survival rate of 484 animals treated with Dipropylene triamine NONOate, a natural donor of nitric oxide, 485 active in acid $\mathrm{PH}$ (common in malaria) whose action, unlike L-arginine, is 486 independent of enzyme activation.

487 Pulmonary findings

488 The mechanisms responsible for triggering the syndrome of respiratory anxiety 489 displayed in malaria patients are multifactorial. However, according to some 490 authors there are no doubts about the participation of free radicals (Gachot et al. 491 1995; Taylor et al. 2006; Gillrie et al. 2007), which directly affect the cell 492 membranes, attacking the endothelium and changing vascular permeability.

493 Among the free radicals involved in this process, NO seems to play an important 494 role. However, the paradox of the actuation of this molecule in pulmonary 495 complications is evident: while some authors suggest that the inhalation of this gas 496 is a potential treatment of these complications (Rabkin et al. 2001; Schreiber et al. 497 2003; McClintock et al. 2007; ter Horst et al. 2007), others blame nitric oxide 
498

499

500

501

502

503

504

505

506

507

508

509

510

511

512

513

514

515

516

517

518

519

520

521

synthesis as responsible for causing the respiratory distress syndrome (Adhikari et al. 2007), in particular as a result of the activation of iNOS (Mikawa et al. 2003; Baron et al. 2004).

Additionally, superoxide radical, stimulated by substances derived from the inflammatory process, such as TNF- $\alpha$, IL-1 $\alpha$ and lipopolysaccharide (through the increase on NADPH-oxidase activity), are also present in the syndrome, which also seems to be related with the increase of nitric oxide synthesis (Muzaffar et al. 2003). However, the reaction between these two free radicals (nitric oxide and superoxide) is known to produce a potent third free radical, peroxynitrite (Katzung and Trevor 2017). Thus, nitric oxide seems to play a fundamental role, once that iNOS activation is associated with the induction of NADPH-oxidase and the production of peroxynitrite (Muzaffar et al. 2003; Adhikari et al. 2007).

As a defense mechanism against the cellular damage caused by oxidative stress, there is an increase in the production of antioxidant molecules both from alveolar surfactant production (which is notoriously hyper secreted), as well as by the increase in antioxidant enzyme activity (Rahman and MacNee 2000; Oury et al. 2002; Christofidou-Solomidou et al. 2003; Kinsella et al. 2005; Saxena et al. 2005; Bein et al. 2009).

In the present study there was no significant variation in the dosages of TEAC and TBARS levels in the control group along the infection period (Fig. 3-4). However, it was observed the occurrence of a positive correlation between these parameters for both samples tested (Additional file Fig. 7-8), suggesting that the increase in oxidative stress resulting from the infection induced the increase of antioxidant defenses, but could not be reversed by it. 
522 Additionally, the behavior of the TBARS vs. TEAC correlations and TBARS vs. Uric

523 acid was similar (Additional file Fig. 3-4), suggesting that uric acid is an important

524 component of the antioxidant defense of these animals, or IRS is associated with

525 the infection. In this sense, the absence of correlation between these parameters

526 found in Group L-ARGININE for both samples is further evidence of the absence of

527 the IRS in animals in this group, probably as a result of vasodynamic effects

528 attributable to NO.

529 Among the treatments, the only one that showed significant correlation between

530 TBARS and PARASITEMIA, was dexamethasone $(r=-0.29, p=0.026$; Additional file

531 Fig. 1) and can suggest that the selective inhibition of iNOS, associated to the anti-

532 inflammatory potential of dexamethasone, decrease the lipid peroxidation even

533 with the increase of parasitemia. This suggestion is reinforced by the finding of

534 negative correlations between TEAC vs. PARASITEMIA and URIC ACID vs.

535 PARASITEMIA (Additional file Fig.15 and 19), since enzymatic antioxidant

536 defenses and IRS suffer direct influence of lipid peroxidation.

537 In this experimental model, considering that all animals were exposed to the same

538 food supply, high values of uric acid indicate the existence of ischemia and 539 reperfusion syndrome (Halliwell and Gutteridge 2015), and may be caused by the 540 decrease of the caliber of blood vessels, by anemia, or by obstruction of the blood

541 flow by the occurrence of cytoadherence.

542 It was found that a significant positive correlation for URIC ACID and TBARS levels 543 in both samples and for both groups CONTROL and DEXAMETHASONE, 544 suggesting that IRS arises from the increased oxidative stress in these animals as 545 a consequence of disease progression, as well as that NO synthesis may not exert 
546 important effect in this case. On the other hand, for group L-ARGININE, in both

547 samples, the values of the coefficient of correlation approached zero, suggesting

548 adequate blood supply to these tissues, possibly as a result of NO-attributable

549 vasodilation.

550 The treatment with L-arginine did not promote any modification in the antioxidant

551 capacity during the period studied (Fig. 3). On the other hand, it has significantly

552 increased lipid peroxidation, but only in the first day of infection (Fig. 4A). The

553 decrease in lipid peroxidation in subsequent days can be explained by the

554 decrease in the IRS, justified by the low levels of uric acid for animals of this group

555 during the entire period of infection (Fig. 6A).

556 The high correlations (moderate to strong) for TEAC vs. URIC ACID in all groups 557 (Additional file Fig. 13) arises from the simple fact that uric acid, by itself, is an

558 antioxidant, in addition of being a marker of IRS. The same is true for the positive

559 correlations between TEAC vs. NN (Additional file Fig.11) and NN vs. URIC ACID

560 (Additional file Fig. 17), displayed by most of the groups.

561 Among the most unusual results, it is noteworthy the absence of differences in the 562 levels of pulmonary nitrites and nitrates, independent of the use of inhibitor 563 (dexamethasone) or stimulator of their synthesis (L-arginine; Fig. 5A). The possible 564 explanations for such phenomena arising out of compensatory physiological 565 effects, such as vasoconstriction caused by the NOS inhibition, which seems to 566 stimulate the production of mediators that cause vasodilation such as acetylcholine 567 and bradykinin, which are bronchoconstrictors nonetheless (Silverthorn 2010). 568 Conversely, it is possible that pulmonary hypertension on malaria, reported by 569 Lacerda et al. (2009), as caused by the inhibition of NO by treatment with 
570 dexamethasone, along with the need of oxygen as a result of hemolysis, stimulates

571 the synthesis of eNOS, which increases the expression of eNOS receptors in the

572 lungs (Beleslin-Čoki et al. 2011).

573 The opposite effect happened for group L-ARGININE, in which it was expected an

574 increase in nitrites and nitrates, but despite the lack of statistical significance, stood

575 numerically below of the other two groups. It is worth mentioning that after formed,

576 L-arginine can follow two paths: the formation of ornithine and urea (action of

577 arginase) or the formation of citrulline and NO (action of NOS). Additionally,

578 interleukins (IL) 13 and 14 act over arginase directing L-arginine to the synthesis of

579 ornithine that is converted, by the action of an aminotransferase, to proline. This

580 route has fibrogenic role, since proline is an essential amino acid in collagen (Lee

581 et al. 2001). On the other hand, cytokines interferon $\mathrm{Y}$ (IFN- $\mathrm{Y}$ ), tumor necrosis

582 factor- $\alpha$ (TNF- $\alpha$ ) and IL-12, optimize the formation of NO and citrulline from the

583 action of iNOS over L-arginine (Hesse et al. 2000). Thus, it is likely that the excess

584 of L-arginine, depending on the profile of cellular response stimulated, follow the

585 arginase route, promoting the clearance of pulmonary nitrites and nitrates (Modolell

586 et al. 1995; Chiaramonte et al. 1999; Hesse et al. 2000; Lee et al. 2001), resulting

587 in fibrinogen synthesis, in an attempt to revert pulmonary damage caused by

588 oxidative stress.

589 Another possibility is that the vasodilation produced by NO excess increase

590 availability of $\mathrm{O}_{2}$, substrate of $\mathrm{NADPH}$ oxidase, resulting in greater production of

591 superoxide radical and, consequently, of peroxynitrite (Muzaffar et al. 2003;

592 Adhikari et al. 2007). According to Wedgwood et al. (2012), peroxynitrite levels 
593 impose a negative feed-back on NOS, i.e., the more peroxynitrite is synthesized, 594 greater inhibition of NOS.

595 Additionally, the absence of differences between the groups for the values of 596 pulmonary NN may be the result of the existence of a complex system of non597 adrenergic non-cholinergic (NANC) neural fibers in the lungs of mammals, capable 598 of producing large quantities of NO (Gaston et al. 1994) and, therefore, to masque 599 NO levels arising from malaria in this tissue. This suggestion is reinforced by the 600 absence of correlation between NN and TBARS levels in all groups for lung 601 samples (Additional file Fig. 5). In contrast, for brain samples, both groups 602 CONTROL and DEXAMETHASONE showed significant positive correlations, while 603 group L-ARGININE showed no correlation between these parameters (Additional 604 file Fig. 6). These data suggest that, at least partially, oxidative stress associated 605 with the development of the disease is derived from the production of NO, as 606 pointed out by several authors, in addition to the participation of IRS (Percário et al. 607 2012), which may have been reversed in the animals treated with L-arginine, due 608 to its vasodilator effect.

609 Cerebral findings

610 Similar to the pulmonary features of the disease, cerebral edema seems to 611 determine the pathological onset of severe malaria. However, the increase of 612 intracranial pressure due to cerebral edema results in greater risk of death. This 613 abnormality is originated from a set of factors that, despite the apparently 614 derangement, act in order to eliminate infection even without the passage of the 615 microorganism to the cerebral tissue. 
616 In this context, NO acts as a key molecule in brain infections. However, it is still

617 unknown if the major problem arises from insufficient concentrations of $\mathrm{NO}$ acting

618 directly in the elimination of the parasite, and for this reason, by selecting more

619 resistant strains of the parasite (Gramaglia et al. 2006), or if the high

620 concentrations of NO, produced as a result of infection by the protozoan parasite,

621 are responsible for the cerebral edema (Favre et al. 1999; Maneerat et al. 2000).

622 In the evaluation of brain oxidative parameters, it was noted an increase in lipid

623 peroxidation for mice treated with dexamethasone in relation to the other groups,

624 mainly in first day post-infection. Nevertheless, the opposite happens with the

625 group of mice treated with L-arginine, where TBARS levels are significantly lower

626 than the other groups (Fig. 4B).

627 The elevation of TBARS levels for the group treated with dexamethasone may

628 result from a technical artifact, as brain tissue is rich in cholesterol and the drug

629 may form cholesterol hydroperoxides, which may react with thiobarbituric acid,

630 greatly increasing the absorbance of brain samples (Lima and Abdalla 2001). A

631 finding that may corroborate this statement are the dosages of TEAC that do not

632 change in the first days of study for all groups (Fig. 3B). The possibility that lipid

633 peroxidation occurs in this initial period by an increase in IRS was eliminated since

634 uric acid values for this group of animals are similar to those of the other groups

635 until the tenth day of infection (Fig. 6B).

636 Notwithstanding, it seems that the oxidative effect of nitric oxide was overcome by

637 its vasodilator effect, since the production of uric acid in mice treated with L-

638 arginine was significantly lower when compared to other groups (Fig. 6B), notably

639 from the $10^{\text {th }}$ day of infection. However, the probable vasodilation presented by 
640 group L-ARGININE caused no changes on the survival rate of these animals (Fig.

$6412)$.

642 The re-establishment of antioxidant capacity can be decisive for the survival of

643 mice infected with $P$. berghei. The antioxidant capacity decreases significantly in all

644 tested groups. However, only for group DEXAMETHASONE this antioxidant

645 capacity is significantly reversed from the $10^{\text {th }}$ day (Fig. 3B), reinforcing the idea of

646 Favre et al. (1999) and Maneerat et al. (2000) that the oxidative stress induced by

647 nitric oxide in cerebral microenvironment contributes to the severity of the disease.

648 Another point that deserves to be highlighted for the group treated with

649 dexamethasone is that, despite the inhibition of iNOS, there was only significant

650 increase in serum uric acid concentration from the $15^{\text {th }}$ day (Fig. 6B), signaling that

651 the beginning of IRS coincides with the starting point of deaths in this group. The

652 finding of positive correlation between TBARS and NN for group

653 DEXAMETHASONE corroborates this observation (Additional file Fig. 6).

654 A factor that may have contributed significantly to the late start of the IRS in this 655 group is the inhibition of the inflammatory process, which is necessary for the 656 occurrence of cytoadherence (Ferreira et al. 2004; Pettersson et al. 2005). 657 Additionally, this is the only group that displays significant positive correlation 658 between URIC ACID and PARASITEMIA (Additional file Fig. 20), reinforcing the 659 idea that IRS occurs on a temporal scale.

660 The absence of correlation between NN and PARASITEMIA for all groups and both 661 samples strongly suggests that NO levels do not influence the evolution of 662 parasitemia (Additional file Fig. 9-10). 
663 Considering the different treatments administered, the more promising results were

664 seen with the dexamethasone treatment, since animals exhibited significantly

665 higher survival rate and decreased progression of parasitemia when compared to

666 the other groups. These data suggest that selective inhibition of iNOS, associated

667 to the anti-inflammatory potential of dexamethasone, might decreased lipid

668 peroxidation even with the increase of parasitemia.

669 In contrast, administration of L-arginine, regardless not significant modification in

670 NN concentrations, promoted vasodilation in both organs, proven by an increase in

671 the concentrations of uric acid, with no effect over the survival rate of these

672 animals.

673 Nevertheless, the cerebral oxidative changes promoted by the administration of

674 dexamethasone were somehow different from the ones presented by other groups.

675 The re-establishment of the cerebral antioxidant capacity after the $10^{\text {th }}$ day of

676 infection is noteworthy, suggesting the participation of oxidative stress in brain as a

677 result of plasmodial infection, as well as the inhibition of brain NO synthesis, which

678 promoted survival rate of almost $90 \%$ of the animals until the $15^{\text {th }}$ day of infection, 679 with possible direct interference of ischemia and reperfusion syndrome, as seen by 680 increased levels of uric acid.

\section{CONCLUSION}

682 Lately, the role of NO in the physiopathogenesis of malaria has been extensively 683 studied. Nevertheless, its precise involvement in the underlying mechanisms of the 684 disease is still controversial. The present study presents the inhibitory effects of 685 dexamethasone on brain nitric oxide synthesis and its relationship to increased 
686 survival in the mice model of malaria. To our best knowledge, it is the first time

687 such results are reported in the scientific literature.

688 Data of the present study showed that iNOS inhibition by dexamethasone

689 promoted an increase in the survival rate of $P$. berghei -infected animals until the

690 point at which it compromised the functioning of the cerebral microcirculation.

691 Indeed, iNOS inhibition by dexamethasone seems to have stimulated a series of

692 redox effects that, if compensatory hyper stimulated, may be responsible for the

693 worsening of the pulmonary symptoms.

694 
695

696

697

698

699

700

701

702

703

704

705

706

707

708

709

710

711

712

713

714

715

716

717

718

719

720

721

722

723

724

725

726

727

728

\section{COMPETING INTERESTS}

The authors declare that they have no competing interests.

\section{FUNDING}

National Counsel of Technological and Scientific Development - CNPq (Brazil) for scholarship (DRM).

\section{AUTHOS' CONTRIBUTION}

SP, MDG and MFD were responsible for the design of the study, data analysis, and for the critical revision of the text. DRM, ARQG, ACMGU, MESF, RSS and JRSV were responsible for the collection of data, statistical study and drafting of the manuscript.

\section{REFERENCES}

Adhikari NK, Burns KE, Friedrich JO, Granton JT, Cook DJ and Meade MO (2007) Effect of nitric oxide on oxygenation and mortality in acute lung injury: systematic review and meta-analysis. British Medical Association 334(7597), 779. doi: 10.1136/bmj.39139.716794.55.

Barnes PJ, Adcock I, Spedding M and Vanhoutte PM (1993) Anti-inflammatory actions of steroids: molecular mechanisms. Trends in pharmacological sciences 14(12), 436-441. doi: 10.1016/0165-6147(93)90184-L.

Baron RM, Carvajal IM, Fredenburgh LE, Liu X, Porrata Y, Cullivan ML and Perrella MA (2004) Nitric oxide synthase-2 down-regulates surfactant protein-B expression and enhances endotoxin-induced lung injury in mice. The FASEB Journal 18(11), 1276-1278. doi: 10.1096/fj.04-1518fje.

Becker K, Tilley L, Vennerstrom JL, Roberts D, Rogerson S and Ginsburg H (2004) Oxidative stress in malaria parasite-infected erythrocytes: host-parasite interactions. International Journal for Parasitology 34(2), 163-189. doi: 10.1016/j.ijpara.2003.09.011.

Bein K, Wesselkamper SC, Liu X, Dietsch M, Majumder N, Concel VJ and Borchers MT (2009) Surfactant-associated protein B is critical to survival in nickelinduced injury in mice. American Journal of Respiratory Cell and Molecular Biology 41(2), 226-236. doi: 10.1165/rcmb.2008-0317OC.

\section{Beleslin-Čokić BB, Čokić VP, Wang L, Piknova B, Teng R, Schechter NA and} Noguchi CT (2011) Erythropoietin and hypoxia increase erythropoietin receptor and nitric oxide levels in lung microvascular endothelial cells. Cytokine 54(2), 129135. doi: 10.1016/j.cyto.2011.01.015. 
Botelho C, Silva COS, Beppu OS, Bogossian M and Vargaftig BB (1996) Edema pulmonar na malária: modulaçäo pela cetirizina / Pulmonary edema in murine malaria: modulation by cetirizine. Jornal Brasileiro de Pneumologia 22(2):69-76.

Brinkmann V, Kaufmann SH, Simon MM and Fischer H (1984) Role of macrophages in malaria: $\mathrm{O}_{2}$ metabolite production and phagocytosis by splenic macrophages during lethal Plasmodium berghei and self-limiting Plasmodium yoelii infection in mice. Infection and Immunity 44(3), 743-746.

Cabrales P, Zanini GM, Meays D, Frangos JÁ and Carvalho LJ (2011) Nitric oxide protection against murine cerebral malaria is associated with improved cerebral microcirculatory physiology. Journal of Infectious Diseases 203(10), 1454-1463. doi: 10.1093/infdis/jir058.

Chatterjee S, Premachandran S, Shukla J and Poduval TB (2007) Synergistic therapeutic potential of dexamethasone and L-arginine in lipopolysaccharideinduced septic shock. Journal of Surgical Research 140(1), 99-108. doi: 10.1016/j.jss.2006.09.002.

Chiaramonte MG, Donaldson DD, Cheever AW and Wynn TA (1999) An IL-13 inhibitor blocks the development of hepatic fibrosis during a T-helper type 2dominated inflammatory response. The Journal of Clinical Investigation 104(6), 777-785. doi: 10.1172/JCI7325.

Chiwakata CB, Hemmer CJ and Dietrich M (2000) High levels of inducible nitric oxide synthase mRNA are associated with increased monocyte counts in blood and have a beneficial role in Plasmodium falciparum malaria. Infection and Immunity 68(1), 394-399. doi: 10.1128/IAI.68.1.394-399.2000.

Christofidou-Solomidou M, Scherpereel A, Wiewrodt R, Ng K, Sweitzer T, Arguiri E and Muzykantov VR (2003) PECAM-directed delivery of catalase to endothelium protects against pulmonary vascular oxidative stress. American Journal of Physiology - Lung Cellular and Molecular Physiology 285(2), L283-L292. doi: 10.1152/ajplung.00021.2003.

\section{Cox F (2002) History of human parasitology. Clinical Microbiology Reviews} 15:595-612. doi: 10.1128/CMR.15.4.595-612.2002.

De Vera ME, Taylor BS, Wang QI, Shapiro RA, Billiar TR and Geller DA (1997) Dexamethasone suppresses iNOS gene expression by upregulating I-kBa and inhibiting NF-kB. American Journal of Physiology - Gastrointestinal and Liver Physiology 273(6), G1290-G1296. doi: 10.1152/ajpgi.1997.273.6.G1290.

Dell RB, Holleran S, Ramakrishnan R (2002) Sample size determination. Institute of Laboratory Animal Resources Journal 43(4):207-13. doi: 10.1093/ilar.43.4.207.

Dey S, Guha M, Alam A, Goyal M, Bindu S, Pal C and Bandyopadhyay U (2009) Malarial infection develops mitochondrial pathology and mitochondrial oxidative stress to promote hepatocyte apoptosis. Free Radical Biology and Medicine 46(2), 271-281. doi: 10.1016/j.freeradbiomed.2008.10.032. 
769

770

771

772

773

774

775

776

777

778

779

780

781

782

783

784

785

786

787

788

789

790

791

792

793

794

795

796

797

798

799

800

801

802

803

804

805

806

807

808

Dhangadamajhi G, Mohapatra BN, Kar SK and Ranjit M (2009) Endothelial nitric oxide synthase gene polymorphisms and Plasmodium falciparum infection in Indian adults. Infection and Immunity 77(7), 2943-2947. doi: 10.1128/IAI.00083-09.

Di Rosa M, Radomski M, Carnuccio R and Moncada S (1990) Glucocorticoids inhibit the induction of nitric oxide synthase in macrophages. Biochemical and Biophysical Research Communications 172(3), 1246-1252.

Dondorp AM, Omodeo-Salé F, Chotivanich K, Taramelli D and White NJ (2003) Oxidative stress and rheology in severe malaria. Redox report 8(5), 292-294. doi: 10.1179/135100003225002934.

Farombi EO, Shyntum YY and Emerole GO (2003) Influence of chloroquine treatment and Plasmodium falciparum malaria infection on some enzymatic and non-enzymatic antioxidant defense indices in humans. Drug and Chemical Toxicology 26(1), 59-71. doi: 10.1081/DCT-120017558.

Favre N, Ryffel B and Rudin W (1999) The development of murine cerebral malaria does not require nitric oxide production. Parasitology 118(2), 135-138. doi: 10.1016/S1286-4579(99)80513-9.

Ferreira MU, da Silva Nunes M and Wunderlich G (2004) Antigenic diversity and immune evasion by malaria parasites. Clinical and Diagnostic Laboratory Immunology 11(6), 987-995. doi: 10.1128/CDLI.11.6.987-995.2004.

Förstermann U and Sessa WC (2012) Nitric oxide synthases: regulation and function. European Heart Journal 33(7), 829-837. doi: 10.1093/eurheartj/ehr304.

Gachot B, Wolff M, Nissack G, Veber B and Vachon F (1995) Acute lung injury complicating imported Plasmodium falciparum malaria. Chest 108(3), 746-749. doi: 10.1378/chest.108.3.746.

Gaston B, Drazen JM, Loscalzo J and Stamler JS (1994) The biology of nitrogen oxides in the airways. American Journal of Respiratory and Critical Care Medicine 149(2), 538-551. doi: 10.1164/ajrccm.149.2.7508323.

Geller DA, Freeswick PD, Nguyen D, Nussler AK, Di Silvio M, Shapiro RA and Billiar TR (1994) Differential induction of nitric oxide synthase in hepatocytes during endotoxemia and the acute-phase response. Archives of Surgery 129(2), 165-171. doi: 10.1001/archsurg.1994.01420260061008.

Gilbert RS and Herschman HR (1993) "Macrophage" nitric oxide synthase is a glucocorticoid-inhibitable primary response gene in 3T3 cells. Journal of Cellular Physiology 157(1), 128-132. doi: 10.1002/jcp.1041570117.

Gillrie MR, Krishnegowda G, Lee K, Buret AG, Robbins SM, Looareesuwan S and Ho M (2007) Src-family kinase-dependent disruption of endothelial barrier function by Plasmodium falciparum merozoite proteins. Blood 110(9), 3426-3435. doi: 10.1182/blood-2007-04-084582.

Gomes BAQ, da Silva LF, Gomes ARQ, Moreira DR, Dolabela MF, Santos RS and Percário S (2015) N-acetyl cysteine and mushroom Agaricus sylvaticus 
809

810

811

812

813

814

815

816

817

818

819

820

821

822

823

824

825

826

827

828

829

830

831

832

833

834

835

836

837

838

839

840

841

842

843

844

845

846

847

848

supplementation decreased parasitaemia and pulmonary oxidative stress in a mice model of malaria. Malaria Journal 14(1), 202. doi: 10.1186/s12936-015-0717-0.

Gramaglia I, Sobolewski P, Meays D, Contreras R, Nolan JP, Frangos JA and Van Der Heyde HC (2006) Low nitric oxide bioavailability contributes to the genesis of experimental cerebral malaria. Nature Medicine 12(12), 1417. doi: 10.1038/nm1499.

Halliwell B and Gutteridge JM (2015) Free radicals in biology and medicine. 5ed. Oxford University Press, USA.

Herrera-Ortíz A, Lanz-Mendoza H, Martínez-Barnetche J, Hernández-Martínez S, Villarreal-Treviño C, Aguilar-Marcelino L and Rodríguez MH (2004) Plasmodium berghei ookinetes induce nitric oxide production in Anopheles pseudopunctipennis midguts cultured in vitro. Insect Biochemistry and Molecular Biology 34(9), 893901. doi: 10.1016/j.ibmb.2004.05.007.

Hesse M, Cheever AW, Jankovic D and Wynn TA (2000) NOS-2 mediates the protective anti-inflammatory and antifibrotic effects of the Th1-inducing adjuvant, IL-12, in a Th2 model of granulomatous disease. The American Journal of Pathology 157(3), 945-955. doi: 10.1016/S0002-9440(10)64607-X.

Huber SM, Uhlemann AC, Gamper NL, Duranton C, Kremsner PG and Lang F (2002) Plasmodium falciparum activates endogenous $\mathrm{Cl}-$ channels of human erythrocytes by membrane oxidation. The EMBO Journal 21(1-2), 22-30. doi: 10.1093/emboj/21.1.22.

Jaramillo M, Godbout M and Olivier M (2005) Hemozoin induces macrophage chemokine expression through oxidative stress-dependent and-independent mechanisms. The Journal of Immunology 174(1), 475-484. doi: 10.4049/jimmunol.174.1.475.

Jaramillo M, Gowda DC, Radzioch D and Olivier M (2003) Hemozoin increases IFN- $\gamma$-inducible macrophage nitric oxide generation through extracellular signalregulated kinase-and NF-kB dependent pathways. The Journal of Immunology 171(8), 4243-4253. doi: 10.4049/jimmunol.171.8.4243.

Katzung BG and Trevor AJ (2017). Farmacologia Básica e Clínica. 13ed. McGraw Hill, Brasil.

Keller CC, Kremsner PG, Hittner JB, Misukonis MA, Weinberg JB and Perkins DJ (2004) Elevated nitric oxide production in children with malarial anemia: hemozoininduced nitric oxide synthase type 2 transcripts and nitric oxide in blood mononuclear cells. Infection and Immunity 72(8), 4868-4873. doi: 10.1128/IAI.72.8.4868-4873.2004.

Kinsella JP, Parker TA, Davis JM and Abman SH (2005) Superoxide dismutase improves gas exchange and pulmonary hemodynamics in premature lambs. American Journal of Respiratory and Critical Care Medicine 172(6), 745749. doi: 10.1164/rccm.200501-146OC. 
849

850

851

852

853

854

855

856

857

858

859

860

861

862

863

864

865

866

867

868

869

870

871

872

873

874

875

876

877

878

879

880

881

882

883

884

885

886

887

888

889

890

Kleinert H, Pautz A, Linker K and Schwarz PM (2004) Regulation of the expression of inducible nitric oxide synthase. European Journal of Pharmacology 500(1-3), 255-266. doi: 10.1016/j.ejphar.2004.07.030.

Kohn HI and Liversedge M (1944) On a new aerobic metabolite whose production by brain is inhibited by apomorphine, emetine, ergotamine, epinephrine, and menadione. Journal of Pharmacology and Experimental Therapeutics 82(3), 292300.

Korhonen R, Lahti A, Hämäläinen M, Kankaanranta H and Moilanen E (2002) Dexamethasone inhibits inducible nitric-oxide synthase expression and nitric oxide production by destabilizing mRNA in lipopolysaccharide-treated macrophages. Molecular Pharmacology 62(3), 698-704. doi: 10.1124/mol.62.3.698.

Kumar S and Bandyopadhyay U (2005) Free heme toxicity and its detoxification systems in human. Toxicology Letters 157(3), 175-188. doi: 10.1016/j.toxlet.2005.03.004.

Lacerda MVGD, Mourão MPG, Santos PJTD and Alecrim MDGC (2009) Algid malaria: a syndromic diagnosis. Revista da Sociedade Brasileira de Medicina Tropical 42(1), 79-81.

Lee CG, Homer RJ, Zhu Z, Lanone S, Wang X, Koteliansky V and Senior RM (2001) Interleukin-13 induces tissue fibrosis by selectively stimulating and activating transforming growth factor $\beta 1$. Journal of Experimental Medicine 194(6), 809-822. doi: 10.1084/jem.194.6.809.

Lima ES and Abdalla DSP (2001) Peroxidação lipídica: mecanismos e avaliação em amostras biológicas/ Lipid Peroxidation: Mechanisms and evaluation in biological samples. Brazilian Journal of Pharmaceutical Sciences 37(3), 293-303.

Luse SA and Miller LH (1971) Plasmodium falciparum malaria. The American Journal of Tropical Medicine and Hygiene 20(5), 655-660. doi:

10.4269/ajtmh.1971.20.655.

Maneerat $Y$, Viriyavejakul P, Punpoowong B, Jones M, Wilairatana P, Pongponratn $E$ and Udomsangpetch $R$ (2000) Inducible nitric oxide synthase expression is increased in the brain in fatal cerebral malaria. Histopathology 37(3), 269-277. doi: 10.1046/j.1365-2559.2000.00989.x.

McClintock DE, Ware LB, Eisner MD, Wickersham N, Thompson BT and Matthay MA (2007) Higher urine nitric oxide is associated with improved outcomes in patients with acute lung injury. American Journal of Respiratory and Critical Care Medicine 175(3), 256-262. doi:10.1164/rccm.200607-9470C.

Mikawa K, Nishina K, Takao Y and Obara H (2003) ONO-1714, a nitric oxide synthase inhibitor, attenuates endotoxin-induced acute lung injury in rabbits.

Anesthesia \& Analgesia 97(6), 1751-1755.

doi:10.1213/01.ANE.0000086896.90343.13.

Miller NJ, Rice-Evans C, Davies MJ, Gopinathan V and Milner A (1993) A novel method for measuring antioxidant capacity and its application to monitoring the 
891

892

893

894

895

896

897

898

899

900

901

902

903

904

905

906

907

908

909

910

911

912

913

914

915

916

917

918

919

920

921

922

923

924

925

926

927

928

929

930

antioxidant status in premature neonates. Clinical Science 84(4), 407-412. doi: 10.1042/cs0840407.

Modolell M, Corraliza IM, Link F, Soler G and Eichmann K (1995) Reciprocal regulation of the nitric oxide synthase/arginase balance in mouse bone marrowderived macrophages by $\mathrm{TH} 1$ and $\mathrm{TH} 2$ cytokines. European Journal of Immunology 25(4), 1101-1104. doi: 10.1002/eji.1830250436.

Muzaffar S, Jeremy JY, Angelini GD, Stuart-Smith K and Shukla N (2003) Role of the endothelium and nitric oxide synthases in modulating superoxide formation induced by endotoxin and cytokines in porcine pulmonary arteries. Thorax $58(7)$, 598-604. doi:10.1136/thorax.58.7.598.

Nahrevanian $\mathrm{H}$ and Dascombe MJ (2006) Simultaneous increases in immunecompetent cells and nitric oxide in the spleen during Plasmodium berghei infection in mice. Journal of Microbiology Immunology and Infection, 39(1), 11.

Narsaria N, Mohanty C, Das BK, Mishra SP and Prasad R (2012) Oxidative stress in children with severe malaria. Journal of Tropical Pediatrics 58(2), 147-150. doi: 10.1093/tropej/fmr043.

Neill AL and Hunt NH (1995) Effects o endotoxin and dexamethasone on cerebral malaria in mice. Parasitology 111(pt4), 443-454.

Omodeo-Salé F, Motti A, Basilico N, Parapini S, Olliaro P and Taramelli D (2003) Accelerated senescence of human erythrocytes cultured with Plasmodium falciparum. Blood 102(2),705-711. doi: 10.1182/blood-2002-08-2437

Otto TD, Böhme U, Jackson AP, Hunt M, Franke-Fayard B, Hoeijmakers WA and Cunningham D (2014) A comprehensive evaluation of rodent malaria parasite genomes and gene expression. BMC Biology 12(1), 86. doi: 10.1186/s12915-0140086-0.

Oury TD, Schaefer LM, Fattman CL, Choi A, Weck KE and Watkins SC (2002) Depletion of pulmonary EC-SOD after exposure to hyperoxia. American Journal of Physiology-Lung Cellular and Molecular Physiology 283(4), L777-L784. doi: 10.1152/ajplung.00011.2002.

Pabón A, Carmona J, Burgos LC and Blair S (2003) Oxidative stress in patients with non-complicated malaria. Clinical Biochemistry 36(1), 71-78. doi: 10.1016/S0009-9120(02)00423-X.

Penet MF, Kober F, Confort-Gouny S, Le Fur Y, Dalmasso C, Coltel N and Viola A (2007) Magnetic resonance spectroscopy reveals an impaired brain metabolic profile in mice resistant to cerebral malaria infected with Plasmodium berghei ANKA. Journal of Biological Chemistry 282(19), 14505-14514. doi: 10.1074/jbc.M608035200.

Percário S, Moreira DR, Gomes BA, Ferreira ME, Gonçalves ACM, Laurindo PS and Green MD (2012) Oxidative stress in malaria. International Journal of Molecular Sciences 13(12), 16346-16372. doi: 10.3390/ijms131216346. 
931

932

933

934

935

936

937

938

939

940

941

942

943

944

945

946

947

948

949

950

951

952

953

954

955

956

957

958

959

960

961

962

963

964

965

966

967

968

969

970

971

Percario S, Vital ACC, Jablonka F (1994) Dosagem do

malondialdeido/Malondialdehyde measurement. Newslab 2(6):46-50.

Peterson TM, Gow AJ and Luckhart S (2007) Nitric oxide metabolites induced in Anopheles stephensi control malaria parasite infection. Free Radical Biology and Medicine 42(1), 132-142. doi: 10.1016/j.freeradbiomed.2006.10.037.

Pettersson F, Vogt AM, Jonsson C, Mok BW, Shamaei-Tousi A, Bergström S and Wahlgren M (2005) Whole-body imaging of sequestration of Plasmodium falciparum in the rat. Infection and Immunity 73(11), 7736-7746. doi: 10.1128/IAI.73.11.7736-7746.2005

Pfeilschifter J and Schwarzenbach H (1990) Interleukin 1 and tumor necrosis factor stimulate cGMP formation in rat renal mesangial cells. Federation of European Biochemical Societies Letters 273(1-2), 185-187. doi: 10.1016/00145793(90)81080-8.

Planche T, Macallan DC, Sobande T, Borrmann S, Kun JF, Krishna S and Kremsner PG (2010) Nitric oxide generation in children with malaria and the NOS2G-954C promoter polymorphism. American Journal of PhysiologyRegulatory, Integrative and Comparative Physiology 299(5), R1248-R1253. doi: 10.1152/ajpregu.00390.2010.

Potter SM, Mitchell AJ, Cowden WB, Sanni LA, Dinauer M, De Haan JB and Hunt $\mathrm{NH}$ (2005) Phagocyte-derived reactive oxygen species do not influence the progression of murine blood-stage malaria infections. Infection and Immunity 73(8), 4941-4947. doi: 10.1128/IAI.73.8.4941-4947.2005.

Rabkin DG, Sladen RN, DeMango A, Steinglass KM and Goldstein DJ (2001) Nitric oxide for the treatment of postpneumonectomy pulmonary edema. The Annals of thoracic surgery 72(1), 272-274. doi: 10.1016/S0003-4975(01)02476-6.

Radomski MW, Palmer RM and Moncada S (1990) Glucocorticoids inhibit the expression of an inducible, but not the constitutive, nitric oxide synthase in vascular endothelial cells. Proceedings of the National Academy of Sciences 87(24), 1004310047.

Rahman I and MacNee W (2000) Oxidative stress and regulation of glutathione in lung inflammation. European Respiratory Journal 16(3), 534-554. doi: 10.1034/j.1399-3003.2000.016003534.x.

Re R, Pellegrini N, Proteggente A, Pannala A, Yang M and Rice-Evans C (1999) Antioxidant activity applying an improved ABTS radical cation decolorization assay. Free Radical Biology and Medicine 26(9-10), 1231-1237. doi: 10.1016/S0891-5849(98)00315-3.

Saeftel M, Krueger A, Arriens S, Heussler V, Racz P, Fleischer B and Hoerauf A (2004) Mice deficient in interleukin-4 (IL-4) or IL-4 receptor a have higher resistance to sporozoite infection with Plasmodium berghei (ANKA) than do naive wild-type mice. Infection and Immunity 72(1), 322-331. doi: 10.1128/IAI.72.1.322331.2004. 
972

973

974

975

976

977

978

979

980

981

982

983

984

985

986

987

988

989

990

991

992

993

994

995

996

997

998

999

1000

1001

1002

1003

1004

1005

1006

1007

1008

1009

1010

1011
Saxena S, Kumar R, Madan T, Gupta V, Muralidhar K and Sarma PU (2005)

Association of polymorphisms in pulmonary surfactant protein A1 and A2 genes

with high-altitude pulmonary edema. Chest 128(3), 1611-1619. doi:

10.1378/chest.128.3.1611.

Sanni LA, Thomas SR, Tattam BN, Moore DE, Chaudhri G, Stocker R and Hunt $\mathrm{NH}$ (1998) Dramatic changes in oxidative tryptophan metabolism along the kynurenine pathway in experimental cerebral and noncerebral malaria. American Journal of Pathology 152(2), 611-619.

Schreiber MD, Gin-Mestan K, Marks JD, Huo D, Lee G and Srisuparp P (2003) Inhaled nitric oxide in premature infants with the respiratory distress syndrome. New England Journal of Medicine 349(22), 2099-2107. doi: 10.1056/NEJMoa031154.

Silverthorn DU. Fisiologia humana: uma abordagem integrada/Human physiology: an integrated approach. 5ed. Porto Alegre: Artmed; 2010.

Skimming JW, Nasiroglu O, Huang CJ, Wood CE, Stevens BR, Haque IU and Sarcia PJ (2003) Dexamethasone suppresses iNOS yet induces GTPCH and CAT2 mRNA expression in rat lungs. American Journal of Physiology-Lung Cellular and Molecular Physiology 285(2), L484-L491. doi: 10.1152/ajplung.00433.2002.

Sohail M, Kaul A, Raziuddin M and Adak T (2007) Decreased glutathione-Stransferase activity: Diagnostic and protective role in vivax malaria. Clinical Biochemistry 40(5-6), 377-382. doi: 10.1016/j.clinbiochem.2007.01.005.

Suresh KP (2011) An overview of randomization techniques: an unbiased assessment of outcome in clinical research. Journal of Human Reproductive Sciences 4(1), 8. doi: 10.4103/0974-1208.82352.

Syarifah HP, Hayano M and Kojima S (2003) Cytokine and chemokine responses in a cerebral malaria-susceptible or-resistant strain of mice to Plasmodium berghei ANKA infection: early chemokine expression in the brain. International Immunology 15(5), 633-640. doi: 10.1093/intimm/dxg065.

Taylor WR, Cañon V and White NJ (2006) Pulmonary manifestations of malaria. Treatments in Respiratory Medicine 5(6), 419-428.

ter Horst SA, Walther FJ, Poorthuis BJ, Hiemstra PS and Wagenaar GT (2007) Inhaled nitric oxide attenuates pulmonary inflammation and fibrin deposition and prolongs survival in neonatal hyperoxic lung injury. American Journal of

Physiology-Lung Cellular and Molecular Physiology 293(1), L35-L44. doi: 10.1152/ajplung.00381.2006.

Vale VV, Vilhena TC, Trindade RCS, Ferreira MRC, Percário S, Soares LF, Pereira WLA, Brandão GC, Oliveira AB, Dolabela MF and De Vasconcelos F (2015) Antimalarial activity and toxicity assessment of Himatanthus articulatus, a plant used to treat malaria in the Brazilian Amazon. Malaria Journal 14(1), 132. doi:

10.1186/s12936-015-0643-1. 
1012

1013

1014

1015

1016

1017

1018

1019

1020

1021

1022

1023

1024

1025

1026

1027

1028

1029

1030

1031

1032

1033

1034

1035

1036

1037

1038

1039

1040

1041

1042

1043

1044

1045

1046

1047

1048

1049 van der Heyde HC, Gu Y, Zhang Q, Sun G and Grisham MB (2000) Nitric oxide is neither necessary nor sufficient for resolution of Plasmodium chabaudi malaria in mice. The Journal of Immunology 165:3317-23. doi: 10.4049/jimmunol.165.6.3317.

Walker G, Pfeilschifter J and Kunz D (1997) Mechanisms of suppression of inducible nitric-oxide synthase (iNOS) expression in interferon (IFN)- $\mathrm{y}$-stimulated RAW 264.7 cells by dexamethasone: evidence for glucocorticoid-induced degradation of iNOS protein by calpain as a key step in post-transcriptional regulation. Journal of Biological Chemistry 272(26), 16679-16687. doi: 10.1074/jbc.272.26.16679.

Wedgwood S, Lakshminrusimha S, Farrow KN, Czech L, Gugino SF, Soares F and Steinhorn $\mathrm{RH}$ (2012) Apocynin improves oxygenation and increases eNOS in persistent pulmonary hypertension of the newborn. American Journal of Physiology-Lung Cellular and Molecular Physiology 302(6), L616-L626. doi: 10.1152/ajplung.00064.2011.

Wilmanski J, Siddiqi M, Deitch EA and Spolarics Z (2005) Augmented IL-10 production and redox-dependent signaling pathways in glucose-6-phosphate dehydrogenase-deficient mouse peritoneal macrophages. Journal of leukocyte biology 78(1), 85. doi: 10.1189/jlb.0105010.

World Health Organization. WHO Global Malaria Program. World Malaria Report 2017. https://www.who.int/malaria/publications/world-malaria-report-2017/en/. Accessed 08 December 2018.

World Health Organization. WHO Global Malaria Program. World Malaria Report 2014. http://www.who.int/malaria/publications/world malaria report 2014/en/. Accessed 16 December 2015.

World Health Organization. WHO Global Malaria Program. World Malaria Report 2011. http://www.who.int/malaria/publications/atoz/978924156. Accessed 21 March 2013.

Yazar S, Kilic E, Saraymen R and Ozbilge H (2004) Serum malondialdehyde levels in patients infected with Plasmodium vivax. The West Indian Medical Journal 53(3), 147-149.

Yeo TW, Lampah DA, Gitawati R, Tjitra E, Kenangalem E, McNeil YR and Price RN (2007) Impaired nitric oxide bioavailability and L-arginine-reversible endothelial dysfunction in adults with falciparum malaria. Journal of Experimental Medicine 204(11), 2693-2704. doi: 10.1084/jem.20070819.

Yeo TW, Lampah DA, Gitawati R, Tjitra E, Kenangalem E, Piera K and Anstey NM (2008) Angiopoietin-2 is associated with decreased endothelial nitric oxide and poor clinical outcome in severe falciparum malaria. Proceedings of the National Academy of Sciences 105(44), 17097-17102. doi: 10.1073/pnas.0805782105. 
1050

1051

1052

1053

1054

1055

1056

1057

1058

1059

1060

1061

1062

1063

1064

1065

1066

1067

1068

1069

1070

1071

1072

1073

\section{FIGURE LEGENDS}

Figure 1 - Progression of parasitemia in Plasmodium berghei-infected Swiss mice. Animals were pre-treated and received a daily dose of DEXAMETHASONE, L-ARGININE, or PBS (CONTROL). ${ }^{*} p=6.8 \times 10^{-6}$ versus $\mathrm{L}-\mathrm{ARGININE}$ and $\mathrm{p}=7.3 \times 10^{-5}$ versus CONTROL; ${ }^{*} p=2.8 \times 10^{-5}$ versus $L-A R G I N I N E$ and $p=0.0227$ versus CONTROL.

Figure 2 - Survival rate of Plasmodium berghei-infected Swiss mice. Animals were pretreated and received a daily dose of DEXAMETHASONE, L-ARGININE, or PBS (CONTROL).

Figure 3 - Trolox Equivalent Antioxidant Capacity (TEAC) in lungs (A) and brains (B) of Plasmodium berghei-infected Swiss mice. Animals were pre-treated and received a daily dose of DEXAMETHASONE, L-ARGININE, or PBS (CONTROL). " $\mathrm{p}=0.0401$ versus DEXAMETHASONE; * $p=0.0281$ versus $L-A R G I N I N E$ and $p=0.0033$ versus CONTROL; $€$ $p=0.0360$ versus $L-A R G I N I N E$ and $p=0.0261$ versus DEXAMETHASONE; ${ }^{*} p=0.0357$ versus $L-A R G I N I N E$ and $p=0.0005$ versus CONTROL.

Figure 4 - Thiobarbituric Acid Reactive Substances (TBARS) in lungs (A) and brains (B) of Plasmodium berghei-infected Swiss mice. Animals were pre-treated and received a daily dose of DEXAMETHASONE, L-ARGININE, or PBS (CONTROL). ${ }^{€} \mathrm{p}=0.0294$ versus CONTROL; \# $\mathrm{p}=0.0282$ versus DEXAMETHASONE; * $\mathrm{p}=0.0005$ versus DEXAMETHASONE and $p=0.0029$ versus CONTROL; ${ }^{*} p=0.0060$ versus CONTROL.

Figure 5 - Nitrites and Nitrates in lungs (A) and brains (B) of Plasmodium berghei-infected Swiss mice. Animals were pre-treated and received a daily dose of DEXAMETHASONE, L-ARGININE, or PBS (CONTROL). ${ }^{\#} p=0.0005$ versus L-ARGININE and $p=0.0394$ versus DEXAMETHASONE; * $\mathrm{p}=3.1 \times 10^{-5}$ versus DEXAMETHASONE and $\mathrm{p}=1.5 \times 10^{-4}$ versus CONTROL; ${ }^{\epsilon} \mathrm{p}=3.4 \times 10^{-6}$ versus $\mathrm{L}-\mathrm{ARG}$ ININE and $\mathrm{p}=5.0 \times 10^{-4}$ versus CONTROL; $*$ 
$1074 \mathrm{p}=3.6 \times 10^{-4}$ versus $\mathrm{L}-\mathrm{ARGININE}$ and $\mathrm{p}=4.6 \times 10^{-4}$ versus CONTROL; ${ }^{c} \mathrm{p}=0.0058$ versus $\mathrm{L}$ 1075 ARGININE and $\mathrm{p}=0.0201$ versus CONTROL.

1076 Figure 6 - Uric Acid levels in lungs (A) and brains (B) of Plasmodium berghei-infected 1077 Swiss mice. Animals were pre-treated and received a daily dose of DEXAMETHASONE, 1078 L-ARGININE, or PBS (CONTROL). ${ }^{*} \mathrm{p}=0.0033$ versus DEXAMETHASONE and $\mathrm{p}=4.3 \times 10^{-6}$ 1079 versus CONTROL; * $\mathrm{p}=0.00058$ versus CONTROL; ${ }^{\epsilon} \mathrm{p}=0.00095$ versus CONTROL and $1080 \mathrm{p}=0.00054$ versus DEXAMETHASONE; ${ }^{*} \mathrm{p}=0.00071$ versus CONTROL and $\mathrm{p}=0.01167$ 1081 versus DEXAMETHASONE; ${ }^{c} p=0.0080$ versus DEXAMETHASONE and $p=0.0024$ versus 1082 L-ARGININE; ${ }^{\varepsilon} p=0.0479$ versus DEXAMETHASONE; ${ }^{\&} p=0.0029$ versus CONTROL and $1083 \mathrm{p}=0.0001$ versus DEXAMETHASONE; $\varepsilon \mathrm{p}=0.0395$ versus CONTROL and $\mathrm{p}=0.0407$ 1084 versus DEXAMETHASONE. 
bioRxiv preprint doi: https://doi.org/10.1101/497966; this version posted December 19,2018 . The copyright holder for this preprint (which was not certified by peer review) is the author/funder. This article is a US Government work. It is not subject to copyright under 17 USC 105 and is also made available for use under a CCO license.

108

ADDITIONAL FILE INFORMATION

1087 FILE NAME: ADDITIONAL FILE 1

1088 FILE FORMAT: .docx

1089 TITLE OF DATA: CORRELATION STUDIES

1090 DESCRIPTION OF DATA: Contain Pearson's correlation studies for all parameters studied 
bioRxiv preprint doi: https://doi.org/10.1101/497966; this version posted December 19, 2018. The copyright holder for this preprint (which was not certified by peer review) is the author/funder. This article is a US Government work. It is not subject to copyright under 17 USC 105 and is also made available for use under a CC0 license.

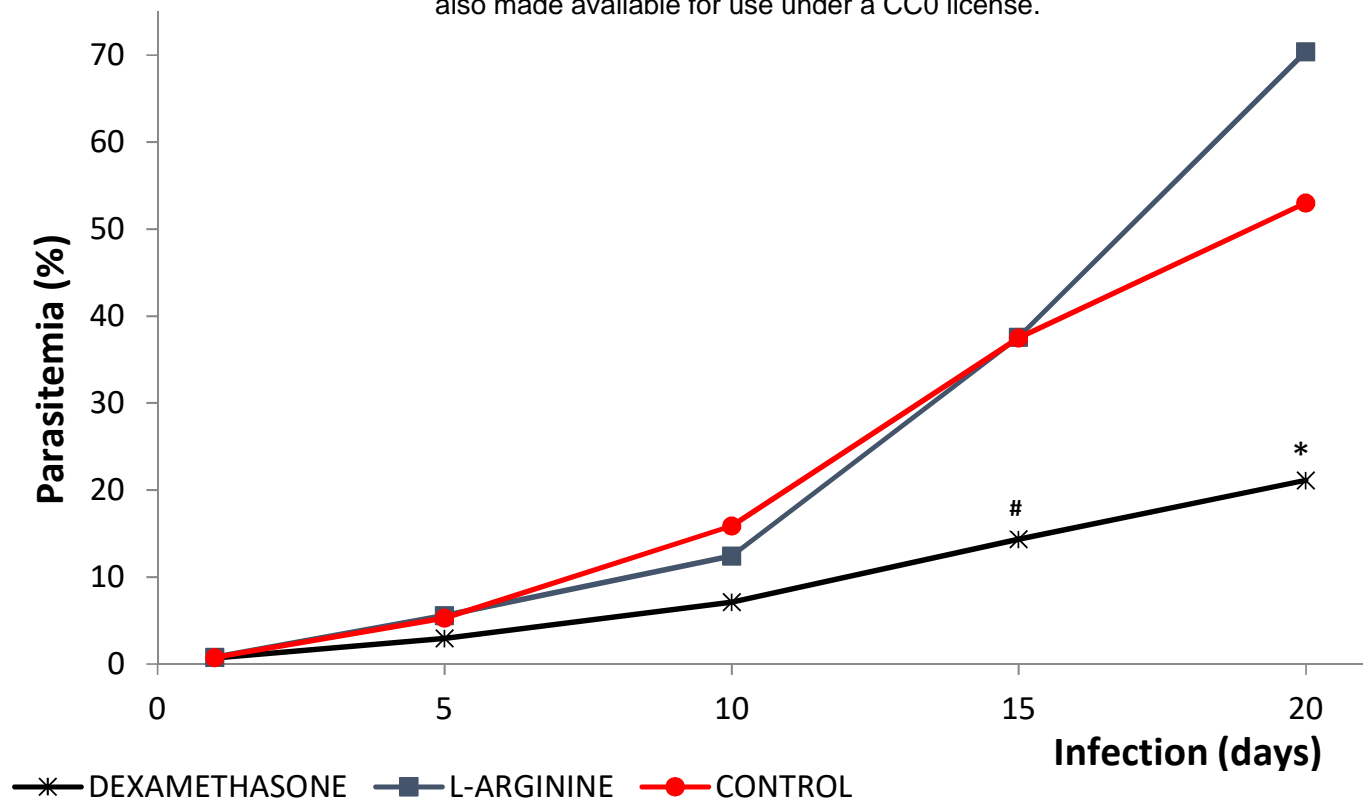


bioRxiv preprint doi: https://doi.org/10.1101/497966; this version posted December 19, 2018. The copyright holder for this preprint (which was not certified by peer review) is the author/funder. This article is a US Government work. It is not subject to copyright under 17 USC 105 and is also made available for use under a CC0 license.

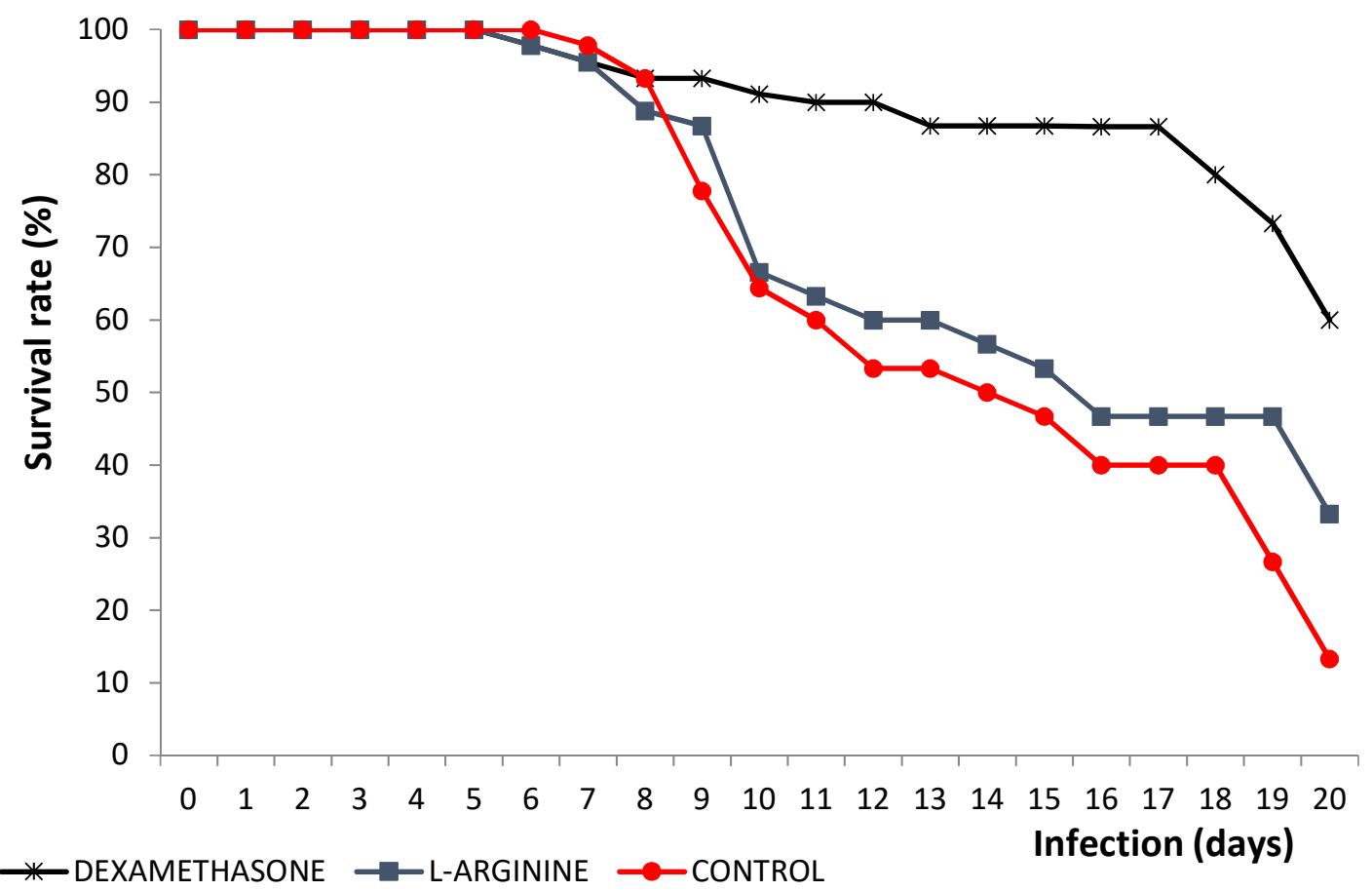


bioRxiv preprint doi: https://doi.org/10.1101/497966; this version posted December 19, 2018. The copyright holder for this preprint (which was not certified by peer review) is the author/funder. This article is a US Government work. It is not subject to copyright under 17 USC 105 and is
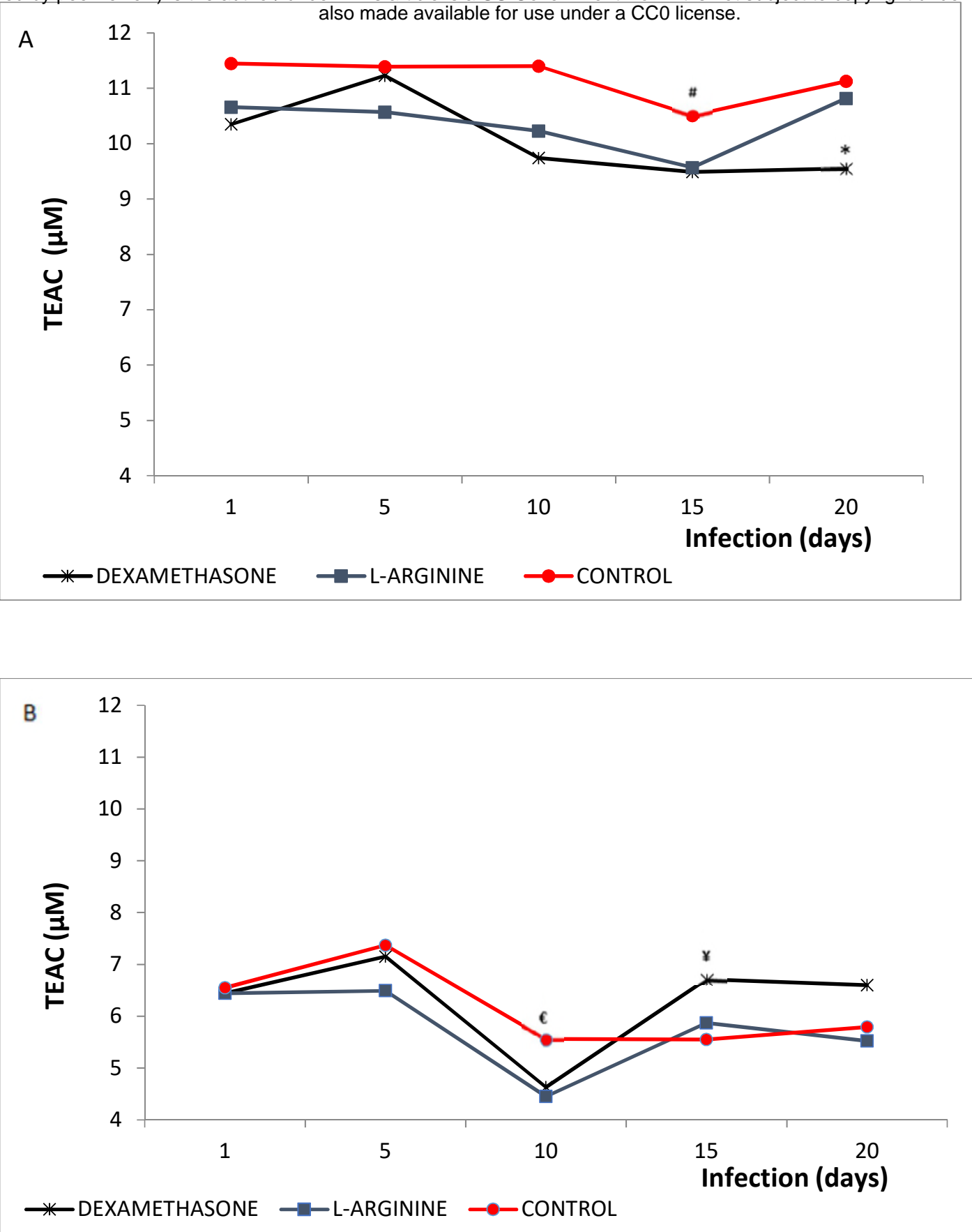
bioRxiv preprint doi: https://doi.org/10.1101/497966; this version posted December 19, 2018. The copyright holder for this preprint (which was not certified by peer review) is the author/funder. This article is a US Government work. It is not subject to copyright under 17 USC 105 and is A $\quad 320 \quad$ also made available for use under a CC0 license.
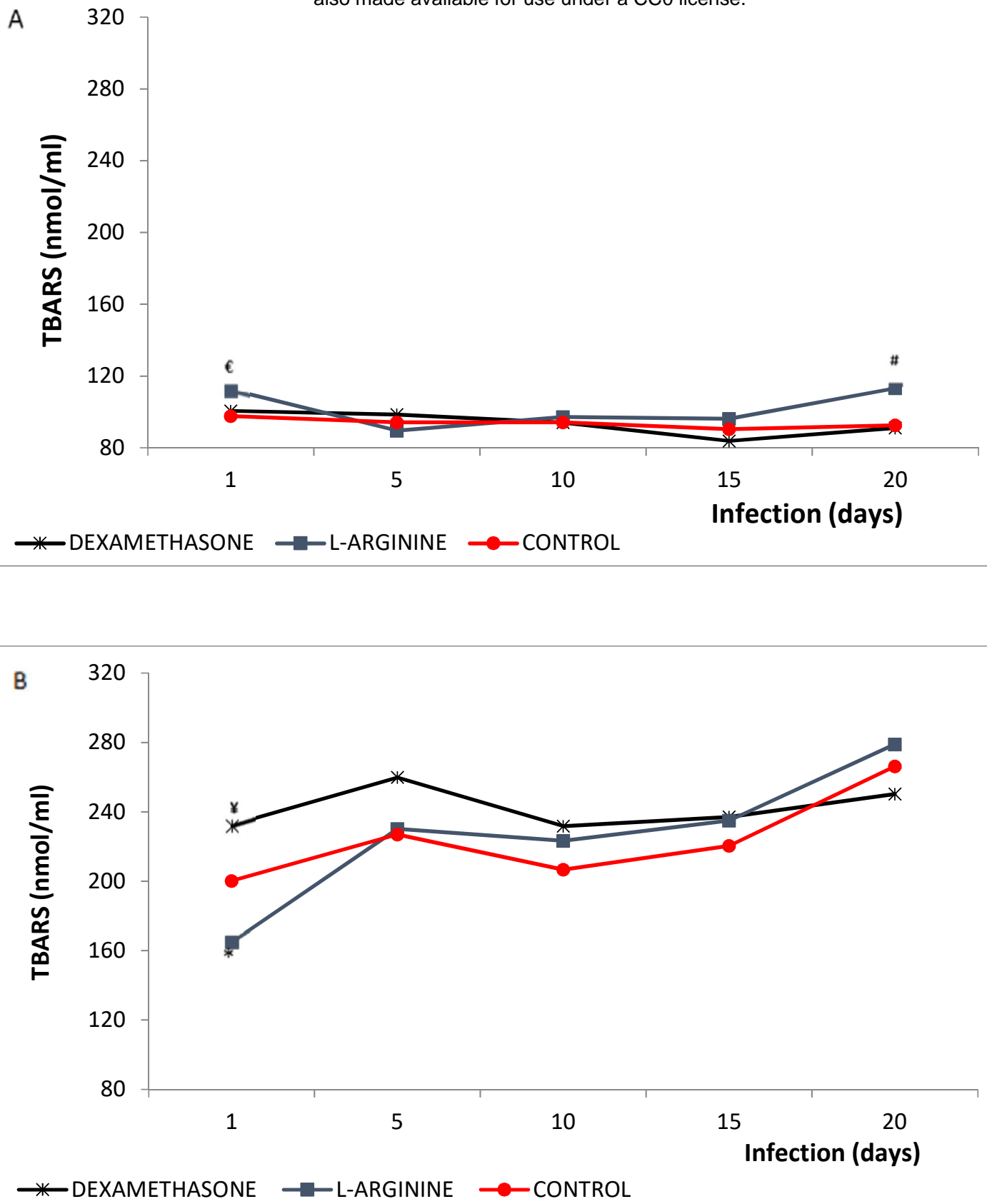
bioRxiv preprint doi: https://doi.org/10.1101/497966; this version posted December 19, 2018. The copyright holder for this preprint (which was not certified by peer review) is the author/funder. This article is a US Government work. It is not subject to copyright under 17 USC 105 and is
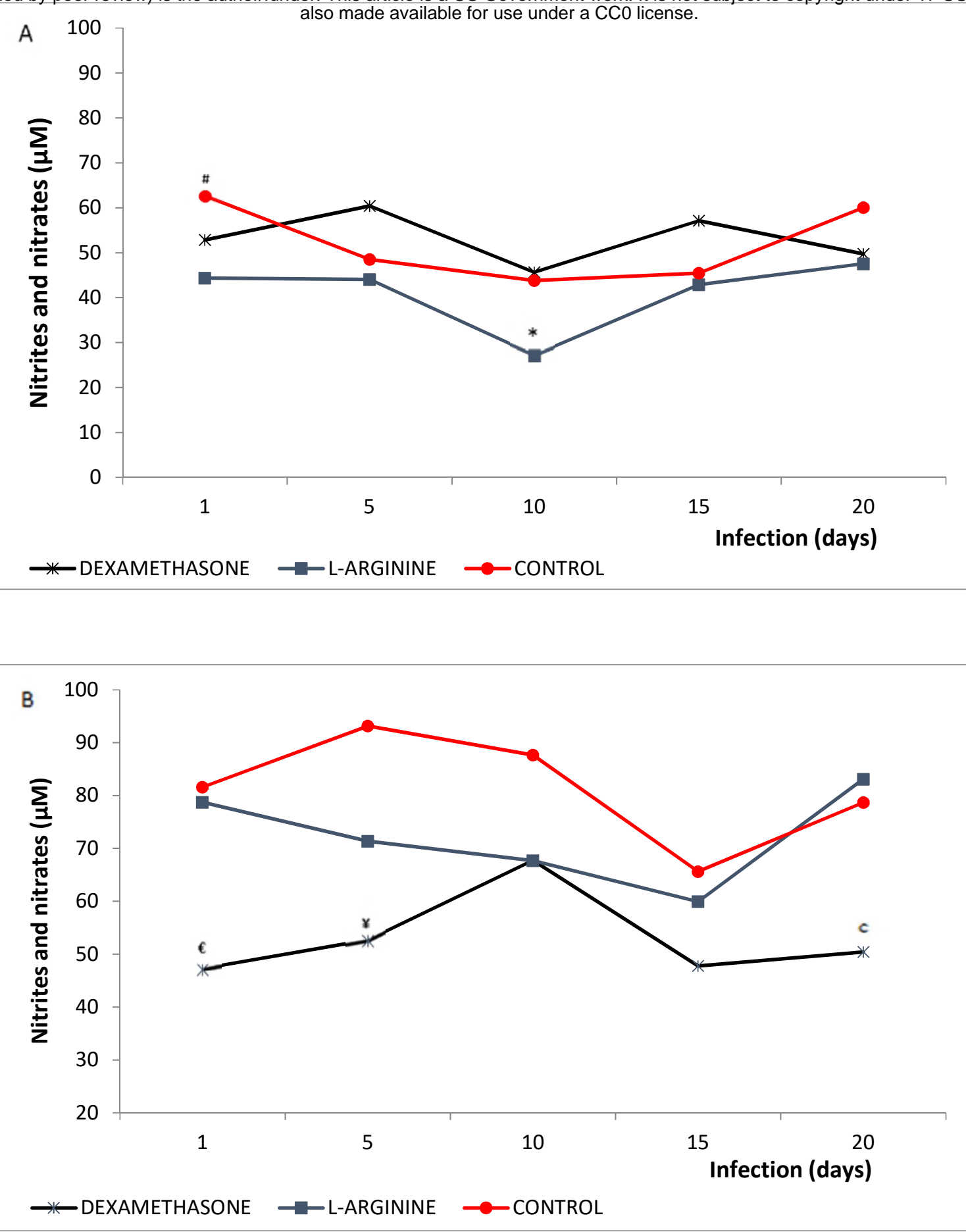
bioRxiv preprint doi: https://doi.org/10.1101/497966; this version posted December 19, 2018. The copyright holder for this preprint (which was not certified by peer review) is the author/funder. This article is a US Government work. It is not subject to copyright under 17 USC 105 and is
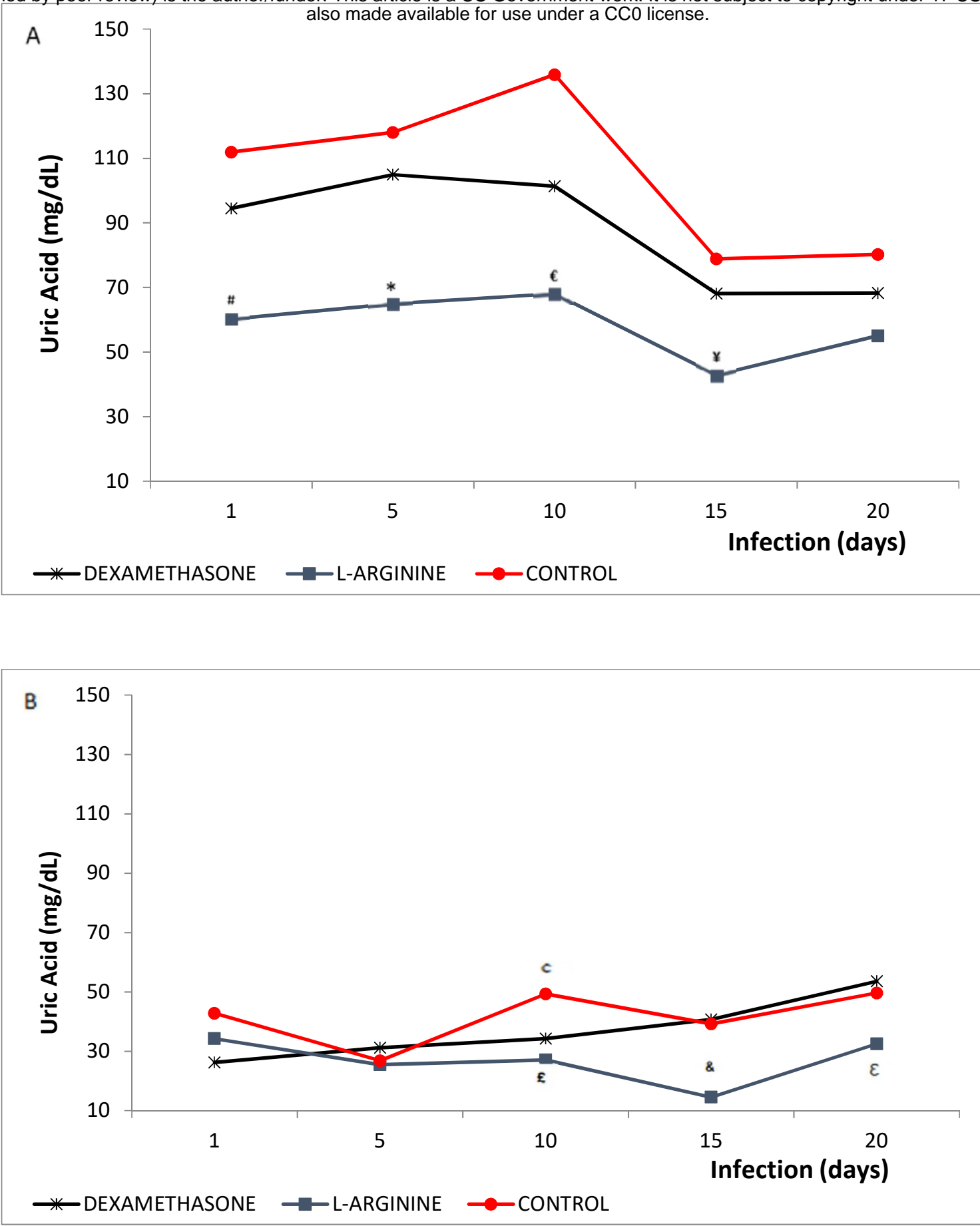